\title{
Confinement effects for rubberised concrete in tubular steel cross-sections under combined loading
}

\author{
A. Mujdeci' ${ }^{1}$ D. V. Bompa ${ }^{1,2}$ - A. Y. Elghazouli ${ }^{1}$
}

Received: 5 November 2020 / Revised: 15 February 2021 / Accepted: 20 February 2021 / Published online: 13 March 2021

(c) The Author(s) 2021

\begin{abstract}
This paper describes an experimental investigation into confinement effects provided by circular tubular sections to rubberised concrete materials under combined loading. The tests include specimens with $0 \%, 30 \%$ and $60 \%$ rubber replacement of mineral aggregates by volume. After describing the experimental arrangements and specimen details, the results of bending and eccentric compression tests are presented, together with complementary axial compression tests on stub-column samples. Tests on hollow steel specimens are also included for comparison purposes. Particular focus is given to assessing the confinement effects in the infill concrete as well as their influence on the axial-bending cross-section strength interaction. The results show that whilst the capacity is reduced with the increase in the rubber replacement ratio, an enhanced confinement action is obtained for high rubber content concrete compared with conventional materials. Test measurements by means of digital image correlation techniques show that the confinement in axial compression and the neutral axis position under combined loading depend on the rubber content. Analytical procedures for determining the capacity of rubberised concrete infilled cross-sections are also considered based on the test results as well as those from a collated database and then compared with available recommendations. Rubber content-dependent modification factors are proposed to provide more realistic representations of the axial and flexural cross-section capacities. The test results and observations are used, in conjunction with a number of analytical assessments, to highlight the main parameters influencing the behaviour and to propose simplified expressions for determining the cross-section strength under combined compression and bending.
\end{abstract}

Keywords Rubberised concrete $\cdot$ Concrete confinement $\cdot$ Infilled steel tubes $\cdot$ Axial-bending interaction $\cdot$ Inelastic response

\section{List of symbols}

Latin uppercase

$A_{\mathrm{c}} \quad$ Concrete area

$A_{\mathrm{p}} \quad$ Inelastic energy

$A_{\mathrm{s}} \quad$ Steel cross-sectional area

$A_{\mathrm{y}} \quad$ Elastic energy

$D \quad$ Diameter

$E_{\mathrm{s}} \quad$ Steel elastic modulus,

D. V. Bompa

d.bompa@surrey.ac.uk

A. Mujdeci

a.mujdeci18@imperial.ac.uk

A. Y. Elghazouli

a.elghazouli@imperial.ac.uk

1 Department of Civil and Environmental Engineering, Imperial College London, London, UK

2 Department of Civil and Environmental Engineering, University of Surrey, Guildford, UK
$E_{\mathrm{rc}} \quad$ Concrete elastic modulus

$L \quad$ Specimen length

$M, M_{\mathrm{i}} \quad$ Bending moment

$M_{\text {max }, \mathrm{R}} \quad$ Maximum moment

$M_{\mathrm{pl}, \mathrm{R},} M_{\mathrm{u}, \mathrm{i}} \quad$ Bending moment capacity

$M_{\text {test }} \quad$ Test bending moment

$N_{\mathrm{pl}, \mathrm{R}}, N_{\mathrm{u}, \mathrm{i}} \quad$ Axial capacity

$N_{\text {res }} \quad$ Sectional analysis predicted strength

$N_{\text {test }} \quad$ Test axial strength

$N_{\text {ST }} \quad$ Cross-sectional capacity hollow steel sections

$W_{\mathrm{pl}} \quad$ Plastic section modulus of

$W_{\mathrm{ps}} \quad$ Steel plastic section modulus,

$W_{\mathrm{psn}} \quad$ Steel plastic section modulus from $2 \times h_{\mathrm{n}}$

$W_{\mathrm{pc}} \quad$ Concrete plastic section modulus,

$W_{\mathrm{pcn}} \quad$ Concrete plastic section modulus from $2 \times h_{\mathrm{n}}$

$\varnothing \quad$ Diameter

Latin lowercase

$e \quad$ Eccentricity

$e_{\text {test }} \quad$ Test eccentricity

$d \quad$ Depth 


$\begin{array}{ll}d_{\mathrm{g}, \max } & \text { Aggregate size } \\ f_{\mathrm{c}, 28 \mathrm{~d}} & \text { Concrete compressive strength } \\ f_{\mathrm{ctr}} & \text { Concrete splitting tensile strength } \\ f_{\mathrm{rc}} & \text { Rubberised concrete compressive strength } \\ f_{\mathrm{c} 0} & \text { Reference concrete compressive strength } \\ f_{\mathrm{y}} & \text { 0.2\% Steel proof yield strength } \\ f_{\mathrm{u}} & \text { Ultimate steel strength, } \\ h & \text { Distance between tension and compression } \\ & \text { fibres } \\ h_{\mathrm{n}} & \text { The distance between the neutral axis and the } \\ & \text { cross-section centreline } \\ u & \text { Axial shortening } \\ u_{\mathrm{i}} & \text { Shortening }\end{array}$

\section{Greek letters}

$\alpha \quad$ Interaction diagram coefficient

$\beta \quad$ Interaction diagram coefficient

$\delta \quad$ Displacement

$\varepsilon \quad$ Strains

$\varepsilon_{1} \quad$ Lateral strain

$\varepsilon_{2} \quad$ Longitudinal strain

$\varepsilon_{\mathrm{cc}, 1} \quad$ Conventional concrete axial strain at peak of confined

$\varepsilon_{\mathrm{c} 0,1} \quad$ Reference concrete axial strain at crushing of

$\varepsilon_{\mathrm{c}} \quad$ Compression strain

$\varepsilon_{\text {rcc1 }} \quad$ Rubberised concrete confined axial strain

$\varepsilon_{\mathrm{rc}, 1} \quad$ Rubberised concrete unconfined crushing strain

$\varepsilon_{\text {rcc,1 }} \quad$ Rubberised concrete strain at peak

$\varepsilon_{\text {rc1,1 }} \quad$ Concrete axial strain at crushing

$\varepsilon_{\mathrm{rc} 1,2} \quad$ Concrete lateral strain at crushing

$\varepsilon_{\mathrm{t}} \quad$ Tension strain

$\varepsilon_{\mathrm{u}} \quad$ Ultimate steel strain

$\eta_{\mathrm{s}} \quad$ Steel confinement coefficient

$\eta_{\mathrm{c}} \quad$ Concrete confinement coefficient

$\theta_{\text {peak }} \quad$ Peak rotation

$\theta_{\max } \quad$ Maximum rotation

$\kappa_{\mathrm{cc}} \quad$ Confinement factor

$\lambda$ Aggregate size factor

$\lambda_{\mathrm{cc}} \quad$ Concrete contribution ratio

$\lambda_{\text {rcc }} \quad$ Confinement effectiveness factor

$\mu_{\mathrm{u}} \quad$ Ductility index

$\mu_{\phi} \quad$ Curvature ductility

$\xi \quad$ Confinement parameter

$\rho_{\mathrm{vr}} \quad$ Rubber content

$\sigma \quad$ Stresses

$\chi_{\text {rcc }} \quad$ Modification factor

$\phi_{\mathrm{y}} \quad$ Yield curvature

$\phi_{\mathrm{p}} \quad$ Plastic curvature

$\phi_{\mathrm{u}} \quad$ Ultimate curvature

\section{Introduction}

The potential benefits of rubberised concrete $(\mathrm{RuC})$ compared with conventional concrete materials (CCMs) were highlighted in various recent investigations [1]. These studies indicated that RuC possesses enhanced ductility, energy absorption, durability and sound insulation, as well as lower unit weight in comparison with CCM [2]. In contrast, the partial replacement of mineral aggregates with rubber particles had a detrimental effect on the fresh and mechanical properties, particularly in terms of the reduction in elastic modulus as well as the compressive and tensile strengths [3].

The merits of RuC materials motivated a number of studies on structural members with confining reinforcement such as stirrups and spiral arrangements. Such reinforced rubberised members (RRuC) were shown to develop nearly twofold the ductility levels of their conventional reinforced concrete (RC) counterparts [4]. Moreover, under reverse cycling loading, $\mathrm{RRuC}$ exhibited an increase in energy dissipation of up to $150 \%$ in comparison with conventional elements [5]. However, the enhancement in ductility and energy dissipation was counterbalanced by a reduction in the loading carrying capacity due to the relatively modest levels of confinement mobilised.

External confinement, such as using fibre-reinforced polymer (FRP), provides a viable approach to recover some or all of the strength loss due to the presence of rubber [6]. FRP laminates were shown in previous studies to improve the capacity of RuC members under combined compression and bending loading and to provide high rotation capacity compared with RRuC members with internal stirrup confinement [7]. The capacity of FRP-confined RuC was between two to four times higher than unconfined RuC when the rubber content was $30 \%$ and $60 \%$, respectively [8].

As an alternative to external FRP or internal hoop confinement, steel tubes can offer a favourable confinement solution [9]. In this case, the congestion of reinforcement in the connection zones can be minimised and the tube also provides a permanent formwork for the concrete core. Additionally, the infilled concrete acts as a resistance mechanism to inward local buckling of the steel tube [10]. In circular concrete-filled steel tube (CFST) specimens, higher levels of circumferential stresses occur in the tube walls, allowing higher confinement effects to develop in the concrete core [11]. As a result, CFST develops significantly higher confinement effects when circular cross-sections are used, in comparison with square or rectangular forms [12]. Square and rectangular rubberised concrete filled steel tubes (RuCFSTs) were shown to exhibit a generally ductile behaviour [13], both under monotonic and cyclic loading with some degradation effects occurring under cyclic conditions due to more pronounced local buckling [14]. 
Axial compression tests on RuCFST stub columns showed that the presence of rubber particles can potentially improve the strength, ductility and energy absorption capacity of such members [15]. For low rubber content ratios, the reduction in strength was counterbalanced by the increase in confinement provided by the circular tube [16]. Displacement ductility ratios and confinement levels for RuCFST were shown to be more than twice those with square or rectangular sections [17]. Eccentric tests on RuCFST columns also indicated improved bending performance and ductility for tubular members compared to conventional concrete specimens [18].

The above-mentioned studies illustrated the potential for using RRuC- and FRP-confined RuC in various structural applications due to their ability to sustain relatively large deformations. The enhancement in performance due to steel tube confinement in compression-dominated CCM members has also been demonstrated in numerous investigations [19]. Although the performance of confined RuCFST has been assessed in several previous studies, this was primarily considering axial compression $[15,18]$, or under modest levels of axial load combined with bending $[13,14,16,20]$. Most studies also investigated the overall response of RuCFST without a detailed assessment of cross-sectional behaviour under combined loading and largely focussed on relatively thick tubular sections and concrete with low rubber content. Importantly, the lack of studies on members with relatively high rubber content, of more than $30 \%$, may in part be attributed to the reduction in concrete strength to levels typically below the limits imposed by various codified provisions [21], hence necessitating the modification of existing design provisions.

This paper examines the confinement effects of rubberised concrete within circular CFST and RuCFST crosssections, through axial, eccentric compression and threepoint bending tests. Particular focus is given to relatively high rubber content of up to $60 \%$ and comparatively thin tubes with diameter-to-thickness ratio larger than 50, for which experimental data are largely lacking. Although circular sections are typically employed for compression elements in practice, bending and low axial load cases are considered in the tests in order to validate the full cross-section strength interaction for generalised loading conditions. Detailed measurements using digital image correlation techniques are employed to assess the surface deformation characteristics and the cross-sectional response of RuCFST under combined loading. Based on the test results, supported by analytical assessments using nonlinear sectional analysis procedures, simplified expressions to determine the axial-moment cross-section strength interaction are proposed, with due account for the influence of key geometric and material properties including the rubber content.

\section{Experimental programme}

The concrete-infilled specimens included $0 \%, 30 \%$ or $60 \%$ rubber content, as a replacement of both fine and coarse mineral aggregates by volume, representing a volumetric rubber ratio $\left(\rho_{\mathrm{vr}}\right)$ of $0,0.3$ and 0.6 , referred to herein as R00, R30 and R60 concrete, respectively. The confinement effects provided by circular tubular sections to rubberised concrete materials under axial compression were assessed by means of $6 \times \varnothing 150 \mathrm{~mm} \times 300 \mathrm{~mm}$ stub columns samples, $2 \times \varnothing 150 \mathrm{~mm} \times 300 \mathrm{~mm}$ hollow steel elements and $9 \times \emptyset 150 \mathrm{~mm} \times 300 \mathrm{~mm}$ cylinders. All cylindrical samples had relatively low aspect ratio $(L / D=2.0)$ and are considered stub-column material tests, which provide useful information on the interaction between the confined infill concrete and the confining steel tube on the cross-section level. In addition to axial compression tests on stub-column samples, $44 \times \emptyset 100 \mathrm{~mm} \times 200$ cylinders and 36 cubes of $100 \times 100 \times 100 \mathrm{~mm}$ were also tested to assess the main material properties of the rubberised and conventional concrete. Tests on six coupons were also carried out in order to assess the uniaxial properties of the steel tube materials.

It should be noted, however, that reliable assessment of axially loaded CFST members, for practical application, would necessitate further experimental assessment on specimens with higher aspect ratios $(L / D \geq 3.0)$ [22]. Stub columns with $L / D \approx 3.0$ would be adequate as they would not fail in global buckling and have a representative aspect ratio to reflect the stress and strain distributions accurately [23]. Conversely, specimens with aspect ratios $L / D<3.0$ may develop elephant foot-type buckling, which can result from end effects [24]. To complement the axial tests from this paper, a database of the results of axial tests on specimens with aspect ratios $L / D \geq 3.0$ was collated [25-28], in order to validate the axial-bending cross-section interaction diagrams described later on in the paper. The number of specimens $(n)$, specimen aspect ratio $(L / D)$, diameter-to-thickness ratio $(D / t)$, steel yield strengths $\left(f_{\mathrm{y}}\right)$ and concrete compressive strengths in each investigation are: (1) $n=15, L / D=3.5, D / t=60-220, f_{\mathrm{y}}=185-363 \mathrm{MPa}$, $f_{\mathrm{c}}=50-80 \mathrm{MPa}[25]$, (2) $n=12, L / D=3.0, D / t=33-67$, $f_{\mathrm{y}}=303 \mathrm{MPa}, f_{\mathrm{c}}=46.8 \mathrm{MPa}[26]$, (3) $n=14, L / D=3.5$, $D / t=165, f_{\mathrm{y}}=200 \mathrm{MPa}, f_{\mathrm{c}}=95-110 \mathrm{MPa}$ [27]; (4) $n=12, L / D=3.0, D / t=55-88, f_{\mathrm{y}}=276-590 \mathrm{MPa}$, $f_{\mathrm{c}}=59.8 \mathrm{MPa}$ [28]. In addition to the above ranges, a set of 25 tests with $L / D=2.0, D / t=21-34, f_{\mathrm{y}}=365 \mathrm{MPa}$ and $f_{\mathrm{c}}=29.1-75.2 \mathrm{MPa}$ were considered [29].

In order to obtain a detailed insight into the confinement effects for cross-sections under combined loading, eccentric compression tests, representing combined compression and bending, on $9 \times \varnothing 150 \mathrm{~mm} \times 600 \mathrm{~mm}$ CFST specimens, 
were carried out. Bending tests on $3 \times \varnothing 150 \mathrm{~mm} \times 600 \mathrm{~mm}$ CFST and $1 \times \emptyset 150 \mathrm{~mm} 600 \mathrm{~mm}$ hollow steel specimens, under three-point loading, were also undertaken in order to validate the full cross-section strength interaction for generalised loading conditions. All the eccentric and bending specimens had an aspect ratio $L / D=4.0$, a range at which the end effects due to friction between the steel tube and loading platens [30] should not be significant. Additionally, such aspect ratios ensure minimum influence from the specimen slenderness on the global behaviour [31].

\subsection{Concrete materials}

Concrete mixes were produced with high strength cement CEM I 52,5, EN 450-1 fineness category $\mathrm{S}$ fly-ash, rubber particles, mineral aggregates, polycarboxylate superplasticiser admixtures and water. The rubber particles consisted of six size ranges: $0-0.5 \mathrm{~mm}, 0.5-0.8 \mathrm{~mm}, 1.0-2.5 \mathrm{~mm}$, 2-4 mm, 4-10 $\mathrm{mm}$ and $10-20 \mathrm{~mm}$. These represented $5 \%, 15 \%, 20 \%, 10 \%$ and $45 \%$ of the total added rubber blend, respectively, and were chosen following a detailed mix optimisation procedure in which a balance between workability and strength loss was sought [2]. The specific gravity of rubber was 1.1, and the fineness modulus of the rubber blend was 4.90. All rubber particles are reported to have $25 \%$ content of carbon black and polymers in the range of $40-55 \%$, whereas the remaining constituents are

Table 1 Mix proportions per cubic metre

\begin{tabular}{llll}
\hline & R00 & R30 & R60 \\
\hline Cement (kg) & 340 & 340 & 340 \\
Fly ash (kg) & 85 & 85 & 85 \\
Aggregates (kg) & & & \\
$0-5 \mathrm{~mm}$ & 820 & 574 & 328 \\
$5-10 \mathrm{~mm}$ & 1001 & 700.7 & 400.4 \\
Rubber (kg) & & & \\
$0-4.0 \mathrm{~mm}$ & - & 74.3 & 148.5 \\
$4.0-10.0 \mathrm{~mm}$ & - & 16.5 & 33 \\
$10-20.0 \mathrm{~mm}$ & - & 74.25 & 148.5 \\
Admixture (1) & & & \\
$($ PL + SPL) & 7.6 & 8.33 & 7.6 \\
w/c & 0.35 & 0.44 & 0.35 \\
\hline
\end{tabular}

softeners and fillers. Fine $(<5 \mathrm{~mm})$ and coarse aggregates $(5-10 \mathrm{~mm})$ had a specific gravity of 2.65 , whilst the rubber particles had a specific gravity of 0.78 . The fineness modulus was 2.35 for fine aggregates and 5.88 for coarse aggregates.

Using the above constituents, three types of concrete materials were prepared with the proportions shown in Table 1. The target concrete strength for the conventional mix was $60 \mathrm{MPa}$. The mixing procedure followed primarily EN 12390-2 guidelines [32] and was adapted to $\mathrm{RuC}$ materials used in previous studies by the authors [1]. The procedure included adding the dry constituents in a rotary mixer until a homogenous dry mix was obtained. After adding half of the water, it was mixed together for about $180 \mathrm{~s}$. In the last stage, the remaining water and admixtures were poured into the container and all constituents were mixed until a homogenous and workable mix was obtained. The fresh concrete was removed from the mixer and placed in plastic forms or steel tubes. Concrete materials placed in cylindrical plastic forms were compacted on a vibrating table, whilst those in steel tubes were compacted using a concrete vibrator. Finally, all samples were covered with plastic sheets and left under standard laboratory conditions. All samples were kept and tested at ambient temperature of $23 \pm 2{ }^{\circ} \mathrm{C}$ and relative humidity $\mathrm{RH}=30-50 \%$.

To obtain the material properties of concrete, cylinders of $\varnothing 100 \mathrm{~mm} \times 200 \mathrm{~mm}$ (diameter $\times$ length) for compressive and splitting strength, and concrete cubes of $100 \mathrm{~mm}$ for compressive strength, were tested. The cylindrical rubberised concrete samples were provided with jubilee clips at the sample ends and then capped at the top surfaces by mortar to avoid local crushing and potential end failure during the compressive strength test. For each batch of concrete, at least three cubes and cylinders were tested at 28 days and at the day of testing. A total of eighty (80) concrete samples were tested, including 44 cylinders and 36 cubes. The cylinder test procedures were undertaken according to EN 12390-2 [32]. The average measured material properties at 28 days are summarised in Table 2. These are the compressive strength $f_{\mathrm{c}, 28 \mathrm{~d}}$, splitting tensile strength $f_{\mathrm{ctr}}$, axial strain at crushing $\varepsilon_{\mathrm{rc} 1,1}$, lateral strain at crushing $\varepsilon_{\mathrm{rc} 1,2}$ and the elastic modulus $E_{\mathrm{rc}}$.

Table 2 Material properties

\begin{tabular}{lllllll}
\hline Unconfined concrete & $f_{\mathrm{c}, 28 \mathrm{~d}}(\mathrm{MPa})$ & $f_{\mathrm{ctr}}(\mathrm{MPa})$ & $\varepsilon_{\mathrm{rc}, 1}(\%)$ & $\varepsilon_{\mathrm{rc}, 2}(\%)$ & $E_{\mathrm{rc}}(\mathrm{Gpa})$ & Slump $(\mathrm{mm})$ \\
\hline R00 & 54.1 & 3.97 & - & - & 35.7 & 125 \\
R30 & 21.2 & 2.21 & 0.13 & 0.09 & 20.1 & 115 \\
R60 & 6.4 & 1.08 & 0.15 & 0.10 & 8.92 & 50 \\
Steel tube & $D / t(\mathrm{~mm} / \mathrm{mm})$ & $f_{\mathrm{y} 0.2 \%}(\mathrm{MPa})$ & $f_{\mathrm{u}}(\mathrm{Mpa})$ & $\varepsilon_{\mathrm{u}}(\%)$ & $E_{\mathrm{s}}(\mathrm{GPa})$ & \\
ST & $152 / 2.8$ & 290 & 421 & 0.14 & 200 & \\
\hline
\end{tabular}




\subsection{Steel coupon tests}

Circular steel tubes of $152 \mathrm{~mm}$ outer diameter and $2.8 \mathrm{~mm}$ wall thickness were used in the experimental assessment. To determine the steel material properties, a total of six coupons were extracted from $2 \times \varnothing 150 \mathrm{~mm} \times 300 \mathrm{~mm}$ steel tubes in accordance with EN 10002-1 [33]. Strain values were obtained both through a video extensometer by assigning a gauge length of $230 \mathrm{~mm}$, and from strain gauges that were positioned at mid-length of each sample following its symmetry centreline. The key material properties of steel tubes obtained from the tensile coupon tests are also summarised in Table 2, where $E_{\mathrm{s}}$ is the elastic modulus, $f_{\mathrm{y}}$ is the $0.2 \%$ steel proof yield strength, $f_{\mathrm{u}}$ is the ultimate steel strength and $\varepsilon_{\mathrm{u}}$ is the ultimate strain.

\subsection{Stub-column tests}

As indicated in Table 3, the sample reference follows the format $X X \mathrm{R} y y \mathrm{E} z z$ in which $\mathrm{XX}$ represents the member type (CF stands for concrete filled tubes and ST stands for steel hollow sections), Ryy is the rubber content in percentage (R00, R30 and R60 for 0\%, 30\% and 60\%, respectively) and Ezz represents the eccentricity level (E00, $0 \mathrm{~mm}$ for axial tests). The sample reference ends with A or B, denoting the testing sequence. For example, "CFR30E00A" represents the first rubberised concrete filled steel tube sample, with $30 \%$ rubber content in uniaxial compression.

As shown in Fig. 1a, short stub-columns of $\varnothing 150 \mathrm{~mm}$ and $300 \mathrm{~mm}$ length were tested under axial loading in a 3500-kN capacity Instron machine. These included nine

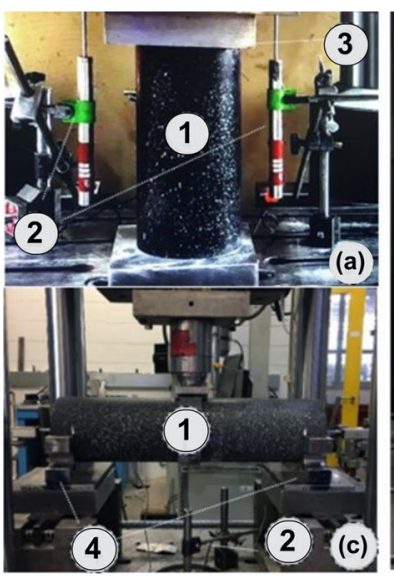

(1) specimen (2) transducers

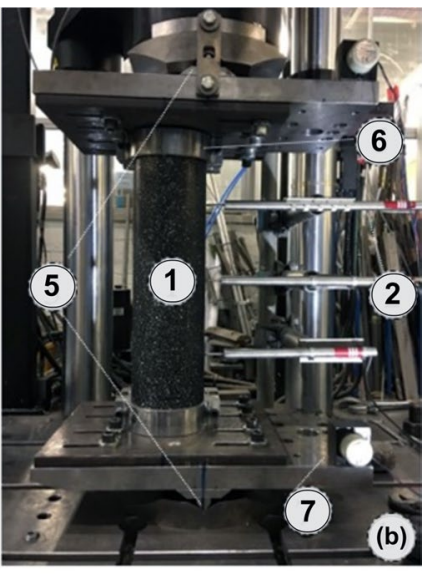

(3) transfer plates 4 bearings
(5) knife edges (6) clamping device (7) inclinometer

Fig. 1 Testing arrangement: a axial tests, $\mathbf{b}$ eccentric tests, $\mathbf{c}$ bending tests

concrete cylinders and six circular concrete filled steel tubes (CFST), using R0, R30 and R60 concrete, as well as two circular hollow steel (CHS) tubes. As shown in the figure, to ensure loading concentricity and reliable boundary conditions, two thick rigid loading plates with dimensions of $200 \mathrm{~mm} \times 200 \mathrm{~mm}$ were used at the top and bottom of each sample. Another $25 \mathrm{~mm} \times 300 \mathrm{~mm} \times 300 \mathrm{~mm}$ plate was placed concentrically between the rigid plates and a $3 \mathrm{D}$ hinge. A displacement rate of $0.25 \mathrm{~mm} / \mathrm{min}$ was used and was increased to $1.0 \mathrm{~mm} / \mathrm{min}$ in the post-peak range up to failure. The same loading procedure was applied for the eccentric and bending tests described below.
Table 3 Results of axial stubcolumn tests

\begin{tabular}{lllllll}
\hline Type of test (-) & $\begin{array}{l}\text { Type of } \\
\text { specimen } \\
(-)\end{array}$ & Specimen ID & $\begin{array}{l}\text { Size }(D \times L) / t \\
(\mathrm{~mm} \times \mathrm{mm} / \mathrm{mm})\end{array}$ & $\rho_{\mathrm{vr}}$ & $e_{\text {test }}(\mathrm{mm})$ & $N_{\text {test }}$ or $P_{\text {test }}(\mathrm{kN})$ \\
\hline Axial & C & R00E00 $^{\mathrm{a}}$ & $150 \times 300 / 2.8$ & 0.0 & 0 & \\
& C & R30E00 $^{\mathrm{a}}$ & $150 \times 300 / 2.8$ & 0.3 & 0 & 903 \\
& $\mathrm{C}$ & R60E00 $^{\mathrm{a}}$ & $150 \times 300 / 2.8$ & 0.6 & 0 & 375 \\
& ST & ST-E00A & $152 \times 300 / 2.8$ & - & 0 & 413 \\
& ST & ST-E00B & $152 \times 300 / 2.8$ & - & 0 & 424 \\
& CF & CFR00E00A & $152 \times 300 / 2.8$ & 0.0 & 0 & 1688 \\
& CF & CFR00E00B & $152 \times 300 / 2.8$ & 0.0 & 0 & 1637 \\
& CF & CFR30E00A & $152 \times 300 / 2.8$ & 0.3 & 0 & 941 \\
CF & CFR30E00B & $152 \times 300 / 2.8$ & 0.3 & 0 & 944 \\
& CF & CFR60E00A & $152 \times 300 / 2.8$ & 0.6 & 0 & 618 \\
CF & CFR60E00B & $152 \times 300 / 2.8$ & 0.6 & 0 & 628 \\
\hline
\end{tabular}

The notations for the type of specimens refer to: $C$-concrete cylinder, $S T$-circular hollow steel tube, $C F$ - circular concrete-filled steel tube. $P_{\text {test }}$ corresponds to the peak axial load $N_{\text {test }}$ for concentric compression tests

${ }^{\mathrm{a}}$ Average values of three tests 


\subsection{Eccentric and bending tests}

Using the same notation described above, the specimen reference follows the format $X X \mathrm{R} y y \mathrm{E} z z$. In the eccentric and bending tests, the eccentricity levels Ezz are as follows: E10, E25 and E50 for $10 \mathrm{~mm}, 25 \mathrm{~mm}$ and $50 \mathrm{~mm}$, respectively, and $\mathrm{E} \infty$ refers to the case of bending only. For example, "CFR30E10" represents a rubberised concrete filled steel tube, with 30\% rubber content, subjected to eccentric compression with $10 \mathrm{~mm}$ eccentricity.

With reference to Fig. 1 b, an additional $9 \times$ CFST specimens of $\varnothing 150 \mathrm{~mm}$ diameter and $600 \mathrm{~mm}$ length were tested. For each eccentricity level, specimens with R0, R30 and R60 concrete were tested in a $2000-\mathrm{kN}$ capacity Instron-T200 servo-controlled hydraulic testing machine. Two steel rings of $50 \mathrm{~mm}$ depth were used to fix the ends of the specimen and acted as clamping devices to the machine plates which ensured pinned-pinned boundary conditions through a set of knife edges. After the specimens were positioned in the testing frame, their position was adjusted to ensure the application of the required eccentricity level. Testing was undertaken in displacement control with the displacement applied incrementally, using the same rates noted above, until the maximum rotation of the end plates was reached.

Another four specimens, including $3 \times \mathrm{CFST}$ of $\varnothing 150 \mathrm{~mm}$ diameter and $600 \mathrm{~mm}$ length as well as one circular hollow section (CHS) specimens, were tested under three-point bending in a 750-kN Mayes testing machine, as shown in Fig. 1c. The clear span between the supports was $500 \mathrm{~mm}$, whilst the load was applied at the specimen mid-length through a loading ring. Half-ring supports were used at the ends. The same displacement control of $0.25 \mathrm{~mm} / \mathrm{min}$ was used as before, increasing to $1.0 \mathrm{~mm} / \mathrm{min}$ at deformations above $20 \mathrm{~mm}$. The tests continued until the support rotation limit was reached. After each test, the outer tube was removed and the failure pattern of the concrete core was examined.

\subsection{Instrumentation}

For the axial compression tests, the $25-\mathrm{mm}$ plate provided a reference to the three displacement transducers (LDVTs) that were placed around the cylindrical samples to record their axial shortening. The lateral displacement of the CFST specimens under eccentric loading was measured by three displacement transducers (LDVTs), and the axial shortening was obtained from the testing machine. Moreover, the end rotations at the loading and base plates were obtained from two inclinometers as shown in the figure. For the bending tests, in-plane displacements were measured at three locations using three transducers (LVDTs), and for comparison purposes, strain gauges were also placed at mid-span.
Besides the direct load, displacement and rotation measurements, a digital image correlation (DIC) system was used to record the detailed deformations and strains. For this, the specimen surface was provided with a fine speckle pattern. In the first stage, a black matte layer was applied to avoid the reflections and then a white speckle pattern was sprayed to obtain randomly distributed dots of $0.5-2.0 \mathrm{~mm}$ diameter (i.e. white polka dots on black background). This is necessary to ensure that the DIC system can track the movement of a specimen surface under applied load. Two DIC cameras with $35 \mathrm{mmf} / 2 \mathrm{D}$ lenses were used with a focal distance of about $2.0 \mathrm{~m}$ during the test, as illustrated in Fig. 2a. Prior to testing, a calibration procedure was undertaken. A recording rate of $0.2 \mathrm{~Hz}$ was used as it represents a good balance between the number of images and characteristic deformation response.

The processed DIC recordings were transformed into strains using assigned virtual gauges that tracked the specimen surface during the tests. To obtain deformations and strains, the programme processes the deformation of the surface within discretised subsets or facet elements of the recorded image. The maximum correlation in each subset corresponds to the displacement, giving vector lengths and directions. These are then differentiated to obtain strain tensors across the specimen surface [2, 34]. As shown in Fig. 2b, for the short axial specimens, 100-mm vertical and $50-\mathrm{mm}$ horizontal gauges were considered in order to describe the axial/longitudinal $\left(\varepsilon_{1}\right)$ and lateral $\left(\varepsilon_{2}\right)$ specimen response, respectively. For the bending and eccentric compression tests, $100-\mathrm{mm}$ virtual gauges were placed parallel to the longitudinal specimen axis at the extreme fibres (Fig. 2c, d).

\section{Test results}

\subsection{Stub-column tests}

\subsubsection{Load shortening response}

Axial compression tests on short stub-columns were carried out to examine the influence of rubber content $\left(\rho_{\mathrm{vr}}\right)$ on the confinement levels developed within the infilled concrete material and, in turn, on the overall strength of the crosssection for the case of pure axial load. For this purpose, it should be noted that these tests were carried out on relatively short elements, with $L / D$ of 2.0. These are therefore considered as stub-column tests, which provide useful information on the interaction between the confined infill concrete and the confining steel tube on the cross-sectional level. However, reliable assessment of axially loaded CFST members, for practical application, would necessitate further dedicated examination and validation for more practical ranges with 
Fig. 2 a Set-up of digital image correlation (DIC) system; virtual gauge locations for: $\mathbf{b}$ axial tests, $\mathbf{c}$ eccentric tests, $\mathbf{d}$ bending tests

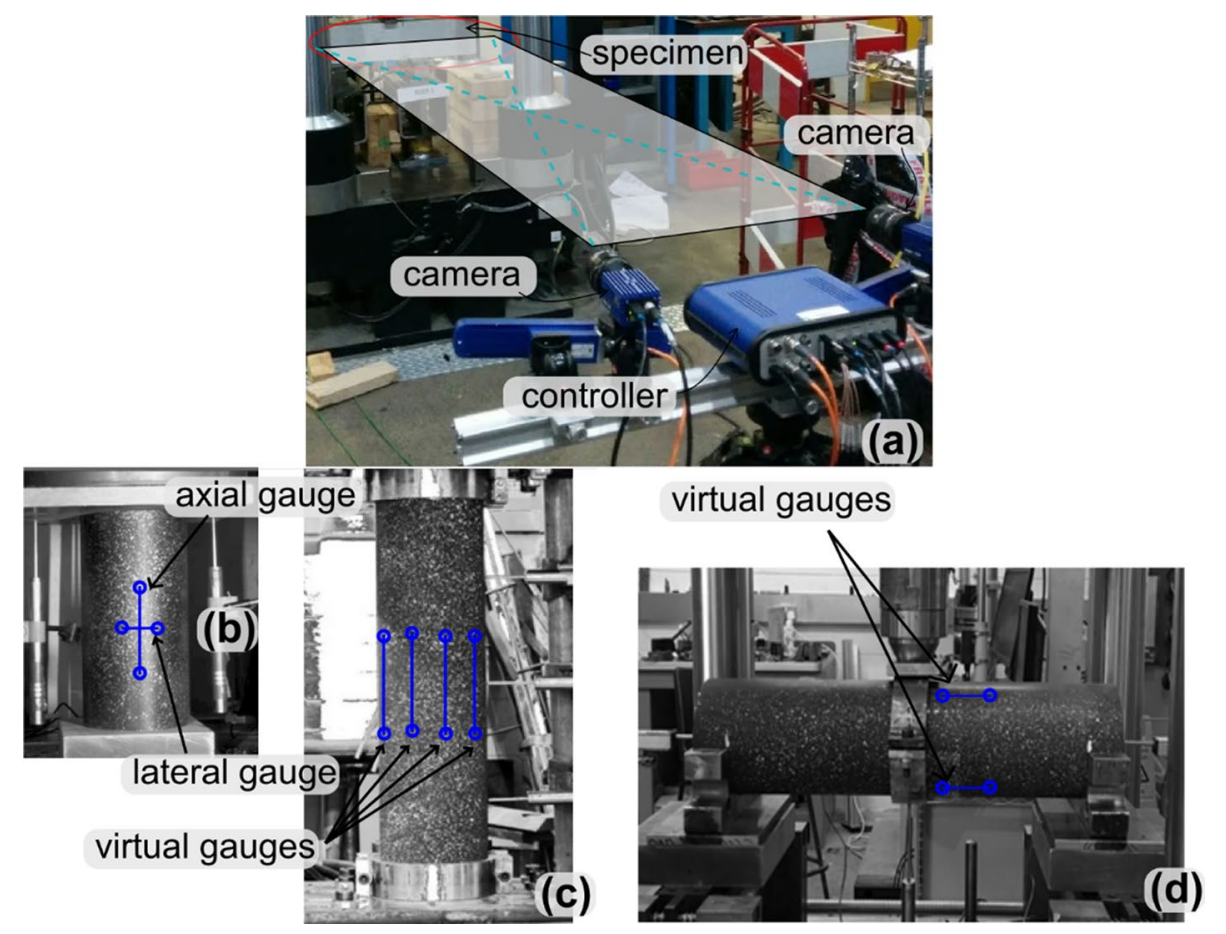

higher $L / D$ ratios, as the latter can have a notable influence on behaviour.

The load-carrying capacity of the samples in compression was found to be a function of the $\rho_{\mathrm{vr}}$ and confinement. This is highlighted through the axial load versus shortening $(N-u)$ relationships shown in Fig. 3 and listed in Table 3. The maximum axial force obtained from the tests $\left(N_{\text {test }}\right)$ is referred to as the experimental axial capacity. The $N_{\text {test }}$ corresponds to the peak load for samples that developed postpeak softening response, whilst $N_{\text {test }}$ was chosen at an axial shortening of $2 \%$ for cases exhibiting post-peak hardening. The average $N_{\text {test }}$ of CFR00E00, CFR30E00 and CFR60E00 were $1663 \mathrm{kN}, 943 \mathrm{kN}$ and $623 \mathrm{kN}$, respectively.

As shown in Fig. 3a, the $N-u$ curve of the conventional CFR00E00 sample is characterised by initial postpeak softening, whilst for CFR30E00 with $30 \%$ rubber the $\mathrm{N}-u$ exhibits post-peak hardening with a small region of softening just after the peak. In contrast, the response of CFR60E00 samples with 60\% rubber exhibited a smooth transition from the elastic to inelastic regimes and gradual post-peak hardening. For example, at a displacement of $u_{1}=25 \mathrm{~mm}$, corresponding to about $8 \%$ axial shortening (Fig. 3a), the reduction in strength for CFR00E00 element was around $25 \%$. In contrast, at the same level of axial shortening, CFR30E00 had a similar strength as at peak, whilst CFR30E00 showed an increase in strength of more than $30 \%$ above first yield corresponding to deviation from elastic behaviour.

The gradual shift in behaviour from post-peak softening to hardening indicates different interaction properties
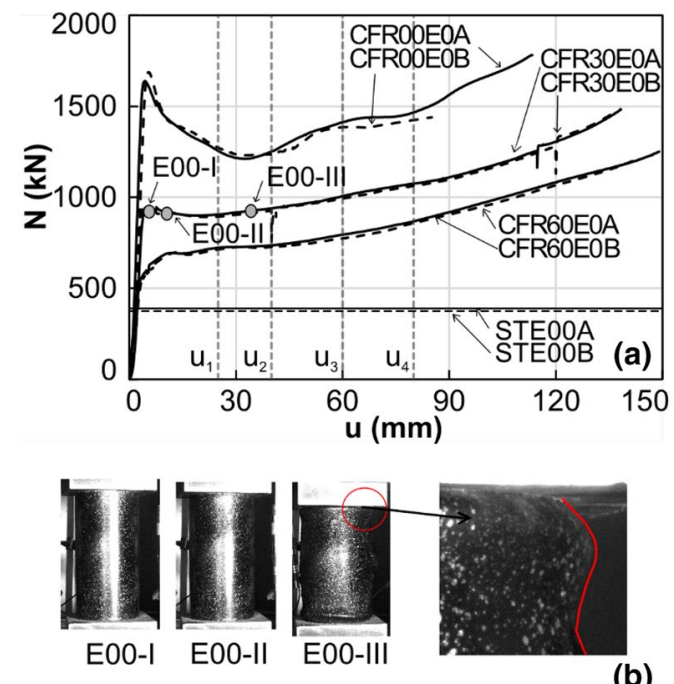

(b)

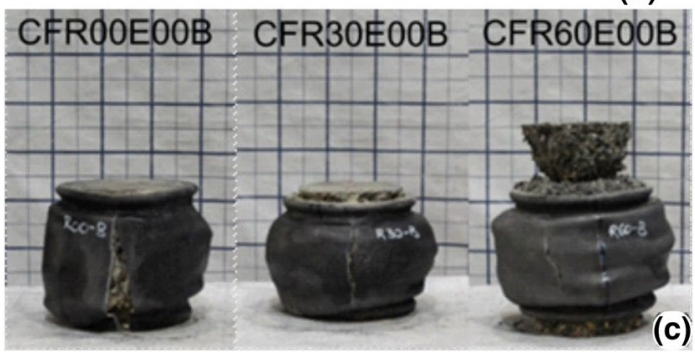

Fig. 3 Stub-column tests a load-axial shortening curves, b deformed shape of CFR30E00B at key stages (I) yield, (II) visible onset of local buckling, and (III) 10\% axial shortening; $\mathbf{c}$ failure of the stub-column samples 
between the concrete infill and the steel tube. On the one hand, as the concrete strength decreases with increased rubber content (e.g. from R00 to R60), the confining pressure required to enhance the post-peak response is reduced. For relatively high-strength CCM, similar to that used herein, minor improvements can occur in the post-peak region, whilst for relatively low-strength concrete such as RuC, only a small amount of confinement pressure is needed to enhance the response.

The infilled samples behaved in a relatively ductile manner under all loading conditions. This is shown in Fig. 3b through the load-displacement $(N-\delta)$ curves and surface deformation characteristics at key displacement levels for selected samples. The characteristic displacement levels denoted with (I), (II) and (III) correspond to yield, visible onset of local buckling and termination of the test, respectively. An assessment of the critical strain $\varepsilon_{\mathrm{cr}}$, using a widely used model [35] and representing initiation of local buckling of a hollow circular section [36] with the geometrical and material properties in Table 2, showed that the critical displacement $\delta_{\text {cr }}$ was between stages (I) and (II) for all tests. This indicates that local buckling always occurred after initiation of yielding (i.e. after stage (I) in Fig. 3b).

\subsubsection{Overall behaviour}

As shown in Fig. 3b, c, for short stub-columns, radial expansion and outward folding failure modes were observed. This is a typical response of short stub-columns in which for relatively thin tubes, local buckling can occur due to end effects [24]. After localised buckling occurred at the CFR30E00B sample top as depicted in Fig. 3b, local folds and axial shortening increased quickly. The ultimate behaviour depended on the rubber content $\left(\rho_{\mathrm{vr}}\right)$, as discussed in Sect. 3.4, being observed with the increase in $\rho_{\mathrm{vr}}$. After unloading and after removing the load transfer plates were removed, the rubberised concrete sprang back indicating a high amount of elastic energy accumulated within the rubberised concrete. As shown in Fig. 3c, this effect increased with the amount of rubber.

It should be noted that the failure mode illustrated in Fig. 3c has the purpose to only show the spring-back response of rubberised concrete in comparison with normal concrete. The photographs were taken after removal from the test rig at 50\% compression (i.e. compressive displacement of $150 \mathrm{~mm}$ corresponding to half of the sample length). Deformations above $3-5 \%$ would not be achievable in practical application within building structures due to imposed rotation limits of connecting members. An axial shortening of about $5 \%$ corresponds to $15-\mathrm{mm}$ axial deformation of the investigated stub members. This point corresponds to Notation E00-I in Fig. 3b.

\subsubsection{Confinement effects}

As described in Sect. 2.2, a DIC system was employed to record surface deformations, from which strains $(\varepsilon)$ can be obtained from assigned virtual gauges. For the axial compression cases, the stresses $(\sigma)$ can be readily determined and used to obtain the stress-strain $(\sigma-\varepsilon)$ curves for each test and then averaged for each set. The $\sigma-\varepsilon$ relationships under axial compression for the unconfined concrete and CFST members are shown in Fig. 4 in order to evaluate the relative confinement effect provided by the tubular steel wall.

The crushing of the R00 high-strength concrete infill was brittle and relatively sudden, and the confinement was activated instantaneously (CFR00E00) as shown in Fig. 4a. In contrast, R30 and R60 concrete materials were relatively ductile with soft crushing behaviour and a flatter post-peak $\sigma-\varepsilon$ response as shown in Fig. 4b, c (CFR30E00, CFR60E00). It is shown that rubberised concrete exhibits a more gradual crushing response, and there is significant elastic energy accumulated within the rubber granules; hence, the interaction with the steel tube is also progressive. The ultimate state was characterised by radial expansion and outward folding of the external tube. As discussed below, the presence of rubber in concrete enhanced the confinement action leading to beneficial effects in terms of both strength and deformation capacity. Based on the measured strains, it was observed that the external confinement enhanced the cross-section capacity of both conventional and rubberised CFST samples under compression in comparison with the corresponding unconfined conventional concrete or rubberised concrete cylinders. As indicated in Table 3 and Fig. 4, the confined-to-unconfined (CFR $x x \mathrm{E} 00 / \mathrm{R} x x \mathrm{E} 00)$ strength ratios were 1.84, 2.51 and 5.51 for samples incorporating R00, R30 and R60 concrete, respectively.

For the conventional CFST samples (CFR00E00), the axial strain at peak $\left(\varepsilon_{\mathrm{cc}, 1}\right)$ was higher by about $40 \%$ compared to the axial strain at crushing $\left(\varepsilon_{\mathrm{c} 0,1}\right)$ of the corresponding unconfined CCM element (R00E00) (Fig. 4a). As shown in Fig. $4 \mathrm{~b}$, the average axial strain at peak $\left(\varepsilon_{\mathrm{rccl}}\right)$ of CFR30 was about $20 \%$ higher than the unconfined crushing strain $\left(\varepsilon_{\mathrm{rc}, 1}\right)$ of its RuC non-filled counterpart (R30E00). Enhancement of more than 50 times in strain at peak $\left(\varepsilon_{\mathrm{rcc}, 1}\right)$, which, due to strain-hardening response, corresponds to ultimate $\left(\varepsilon_{\mathrm{rcc}, \mathrm{u}}\right)$, was obtained for CFR60 compared to $\varepsilon_{\mathrm{rc}, 1}$ of an unconfined RuC sample (R60E00) (see Fig. 4c). As shown in Fig. 4, the lateral strains were also influenced by the presence of rubber and confinement, with improved energy dissipation levels occurring for relatively high $\rho_{\mathrm{vr}}$. The above observations suggest that confinement effectiveness increases significantly with the increase in $\rho_{\mathrm{vr}}$; hence, a highly beneficial effect in terms of general behaviour is obtained for RuCFST in comparison with CFST specimens. 
Fig. 4 Comparative stressstrain curves for CFST and unconfined specimens: a R00, b R30, c R60
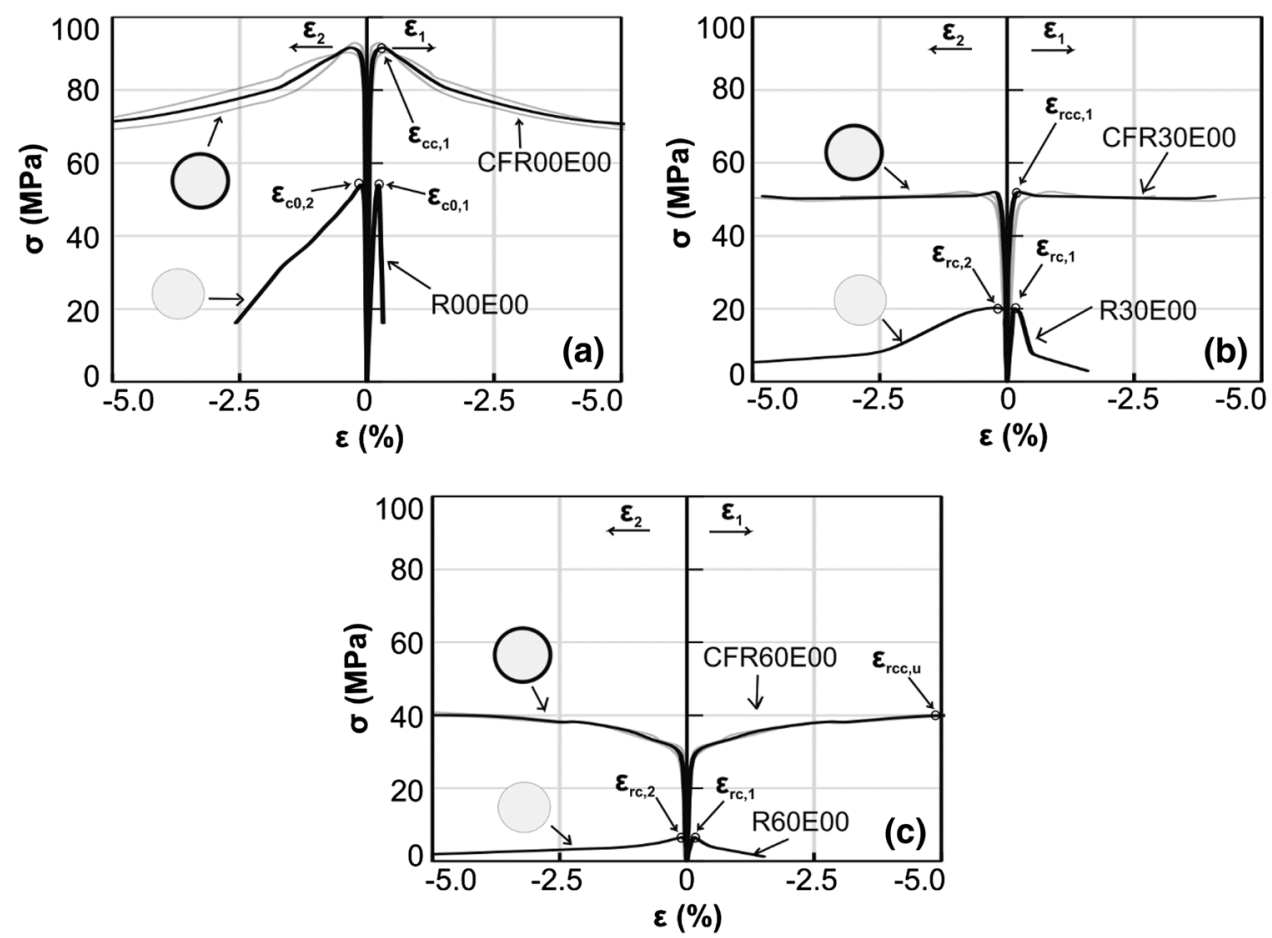

\subsection{Eccentric and bending tests}

\subsubsection{Load-rotation response}

In addition to the axial stub-column tests described above, eccentric and bending tests enable an evaluation of the axial-bending $(N-M)$ interaction curves for CFST cross-sections with CCM and RuC. Figure 5 depicts the applied load $(N)$ versus deflection angle $(\theta)$ relationships for eccentrically loaded specimens and those subjected to bending, whilst a summary of the main test results is given in Table 4. Despite having different aspect ratios than eccentric and bending specimens and for comparative purposes only, the axial capacity of the corresponding short specimens
Fig. 5 Axial load-rotation $(N-$ $\theta)$ curves for tested specimens under axial-bending loading conditions for: a CFR00Ezz, b CFR30Ezz, c CFR60Ezz
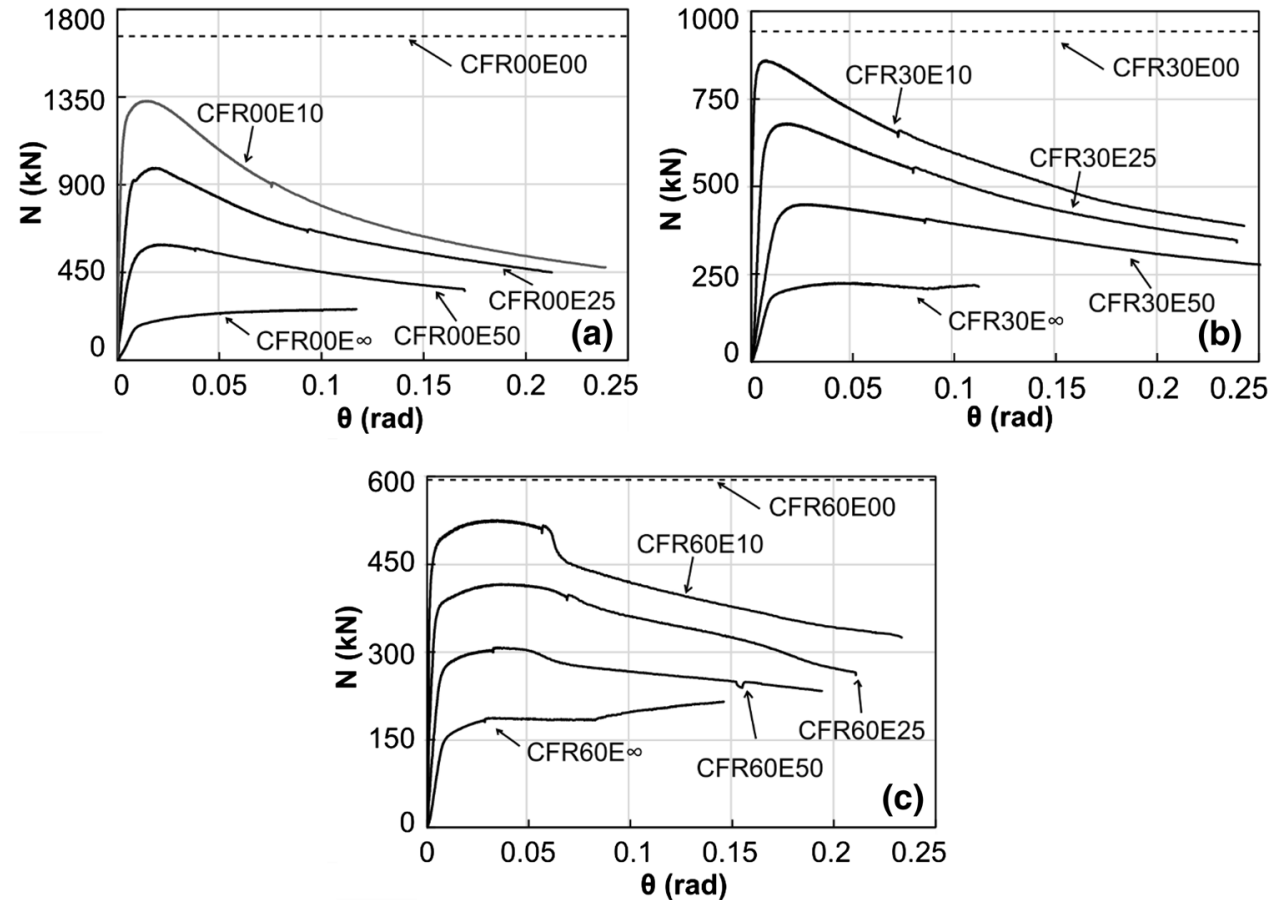
Table 4 Results of eccentric and bending tests

\begin{tabular}{|c|c|c|c|c|c|c|c|c|}
\hline Type of test (-) & $\begin{array}{l}\text { Type of } \\
\text { specimen (-) }\end{array}$ & Specimen ID & $\begin{array}{l}\text { Size }(D \times L) / t \\
(\mathrm{~mm} \times \mathrm{mm} / \mathrm{mm})\end{array}$ & $\rho_{\mathrm{vr}}$ & $e_{\text {test }}(\mathrm{mm})$ & $N_{\text {test }}$ or $\mathrm{P}_{\text {test }}(\mathrm{kN})$ & $M_{\text {test }}(\mathrm{kNm})$ & $\theta_{\text {peak }} / \theta_{\text {max }}(\mathrm{mrad})$ \\
\hline \multirow[t]{9}{*}{ Eccentric } & $\mathrm{CF}$ & CFR00-E10 & $152 \times 600 / 2.8$ & 0.0 & 12 & 1330 & 15.9 & $14 / 45$ \\
\hline & $\mathrm{CF}$ & CFR00-E25 & $152 \times 600 / 2.8$ & 0.0 & 24 & 986 & 23.7 & $19 / 58$ \\
\hline & $\mathrm{CF}$ & CFR00-E50 & $152 \times 600 / 2.8$ & 0.0 & 53.5 & 592 & 31.7 & $23 / 73$ \\
\hline & $\mathrm{CF}$ & CFR30-E10 & $152 \times 600 / 2.8$ & 0.3 & 12 & 859 & 10.3 & $7 / 46$ \\
\hline & $\mathrm{CF}$ & CFR30-E25 & $152 \times 600 / 2.8$ & 0.3 & 23 & 679 & 15.6 & $17 / 67$ \\
\hline & $\mathrm{CF}$ & CFR30-E50 & $152 \times 600 / 2.8$ & 0.3 & 50.5 & 448 & 22.3 & $25 / 115$ \\
\hline & $\mathrm{CF}$ & CFR60-E10 & $152 \times 600 / 2.8$ & 0.6 & 12 & 525 & 6.3 & $34 / 67$ \\
\hline & $\mathrm{CF}$ & CFR60-E25 & $152 \times 600 / 2.8$ & 0.6 & 25 & 415 & 10.3 & $37 / 112$ \\
\hline & $\mathrm{CF}$ & CFR60-E50 & $152 \times 600 / 2.8$ & 0.6 & 53.5 & 307 & 16.5 & $35 / 115$ \\
\hline \multirow[t]{4}{*}{ Bending } & ST & ST-E $\infty$ & $152 \times 600 / 2.8$ & - & - & 140 & 15.5 & $>110$ \\
\hline & $\mathrm{CF}$ & CFR00-E $\infty$ & $152 \times 600 / 2.8$ & 0.0 & - & 217 & 24.9 & $>115$ \\
\hline & $\mathrm{CF}$ & CFR30-E $\infty$ & $152 \times 600 / 2.8$ & 0.3 & - & 219 & 24.7 & $>115$ \\
\hline & $\mathrm{CF}$ & CFR60-E $\infty$ & $152 \times 600 / 2.8$ & 0.6 & - & 187 & 21.0 & $>115$ \\
\hline
\end{tabular}

The notations for the type of specimens refer to: C—concrete cylinder, ST—circular hollow steel tube, CF-circular concrete-filled steel tube. $P_{\text {test }}$ corresponds to the peak axial load $N_{\text {test }}$ for eccentric compression tests, whilst $P_{\text {test }}$ is the peak load applied at mid-span in three-point bending tests; symbol " $>$ " indicates that $\theta_{\max }$ was not achieved and the test was halted due to test rig constraints; $\theta_{\text {peak }}=\theta_{\max }$ in bending tests due to bi-linear hardening response

described above is also shown in the figure. The chord rotation $\theta$ was assessed from the central deflection $\delta$ of the member at its half-length and considering the position of end supports. The value of $\theta_{\text {peak }}$ in Table 4 corresponds to the test peak strength $N_{\text {test }}$, whilst the maximum rotation $\theta_{\text {max }}$ corresponds to a $15 \%$ reduction in capacity for the eccentric tests or when rig support limits are reached in the bending tests.

The eccentric compression tests focussed on nominal eccentricities up to $e=50 \mathrm{~mm}$, which were feasible within the experimental constraints. The test curves are characterised by a post-peak softening response, as shown in Fig. 5a-c, after the peak load was reached. In contrast, specimens subjected to bending only had a largely bi-linear response with hardening. A gradual reduction in peak load $N_{\text {test }}$ is observed with an increase in bending moment as a function of the applied eccentricity (see Table 4). In contrast, $\theta_{\max }$ gradually increased with the eccentricity. Additionally, for the same level of eccentricity, a higher $\theta_{\max }$ was obtained with an increase in $\rho_{\mathrm{vr}}$. For example, for a nominal $e=25 \mathrm{~mm}$, the specimen with $60 \%$ rubber (CFR60E25) had a higher $\theta_{\max }$ by a factor of 1.93 compared to the specimen without rubber (CFR00E25), whilst for CFR30E25 (with $30 \%$ rubber), the increase was about $15 \%$. On the other hand, the specimen in bending (CFR $y y \mathrm{E} \infty$ ) reached $\theta_{\max }$ over 115 mrad and was limited by the testing arrangement.

\subsubsection{Overall behaviour}

As indicated from Figs. 6 and 7, for specimens subjected to eccentric loading, a behaviour governed by crushing of the concrete infill and buckling of the steel tube in compression occurred. Failure of these specimens was by outward folding failure modes of the compression face around their midheight but no fracture occurred in tension. This is shown in Fig. $6 \mathrm{~b}$ for Specimen CFR30E25 at various stages of deformation and in Fig. 7a after the specimens were removed from the rig. A similar folding failure mechanism without tensile fracture was observed for all members (filled tubes and hollow tubes) subjected to three-point bending. As illustrated in Fig. 6c for Specimen CFR30Eo, local buckling was observed around the loading ring on the compressive side of the specimens. Moreover, flexural cracks in the concrete were clearly visible on the tension side at mid-span for concrete-filled specimens after half the steel tube was removed (Fig. 7b).

In the eccentric tests, an increase in replacement ratio indicated a larger compression zone promoted by a gradual reduction in stress after the peak crushing strain was reached. This is compensated by a shorted tension zone, yet with more and finer cracks. The latter occur due to the lower tensile strength of rubberised concrete in comparison with the conventional concrete. This behaviour is described below in Sect. 3.4 through a detailed sectional analysis of eccentric tests. These comments agree with other studies in the literature, which showed that reinforced rubberised concrete members would develop finer cracks at a shorter spacing [37] and in CFST tests with rubberised concrete up to $30 \%$ replacement ratios [17].

As noted in the introduction, this paper examines the interaction between confined rubberised concrete and the confining steel tube for the purpose of assessing the cross-section performance. Although microstructural 
Fig. 6 a Comparative applied load-displacement curves for selected CFR30Ezz specimens and key response characteristics at (I) yield, (II) visible onset of local buckling, and (III) termination of the test; deformed shape of specimens: $\mathbf{b}$ CFR30E25, c CFR30E $\infty$
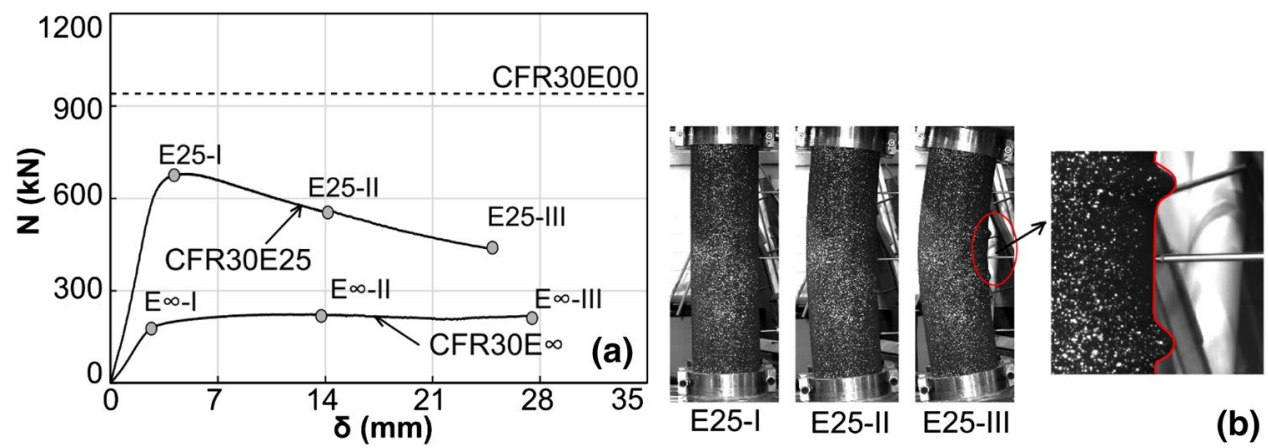

(b)

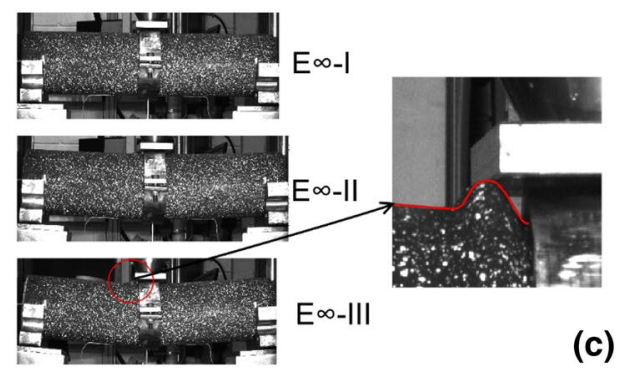

Fig. 7 Failure modes of tested CFST specimens for: a axial tests, $\mathbf{b}$ eccentric tests, $\mathbf{c}$ bending tests

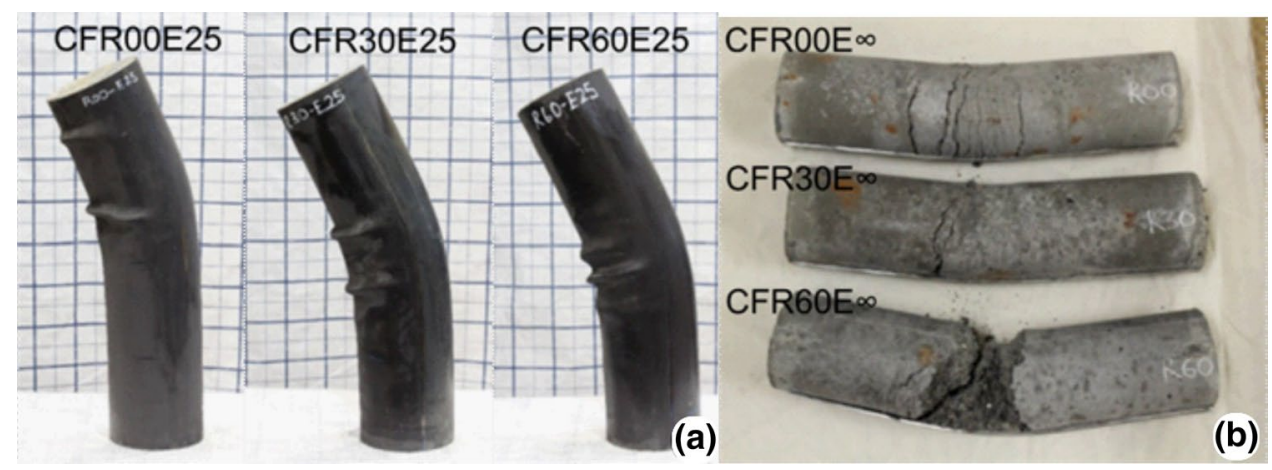

investigations would provide some information regarding the interface transmission zone, this is beyond the scope of the current study. Microstructural investigations have already been carried out on similar RuC mixes in a wider research project [3]. It was shown that rubber and mineral aggregates were well distributed within the investigated surface, yet large gaps were evident between the rubber particles and the surrounding cement paste. Such gaps occur due to the lack of bonding and limited cement hydration at the rubber-cement paste interface zone, or by rubber detachment during specimen preparation, as also shown in other studies [38].

\subsubsection{Confinement effects}

In addition to the confined-to-unconfined strength ratios for which the strength of the unconfined concrete was used as a benchmark, the performance of CFST specimens subjected to both concentric and eccentric compression is assessed as a reference to the strength of the hollow steel section. The concrete contribution ratio $\left(\lambda_{\mathrm{cc}}\right)$ is evaluated as the ratio of the test ultimate capacity of infilled specimens to the crosssectional theoretical capacity of the hollow steel section subjected to concentric or eccentric loading $\left(N_{\mathrm{CFST} \text {,test } /} N_{\mathrm{ST}}\right)$ [39]. It should be noted that $N_{\mathrm{ST}}$ can be determined using codified guidance and depends on the yield strength $f_{\mathrm{y}}$, crosssectional area $A_{\mathrm{s}}$ and plastic section modulus $W_{\mathrm{pl}}$ of the steel tube, as well as on the eccentricity level (Eq. 1a) [40].

The $\lambda_{\mathrm{cc}}$ parameter indicates the contribution of concrete infill to the capacity as well as the synergy between the steel tube and concrete core. Generally, the ultimate capacity and post-peak behaviour are related to the confinement level, and a higher confinement factor would improve ductility [41]. The concrete contribution ratio $\left(\lambda_{\mathrm{cc}}\right)$ is plotted against the confinement factor $(\xi)$ for each specimen in Fig. 8. The parameter $\xi$ in Eq. (1b) is the ratio between the product of yield strength and the cross-sectional area of the steel tube 


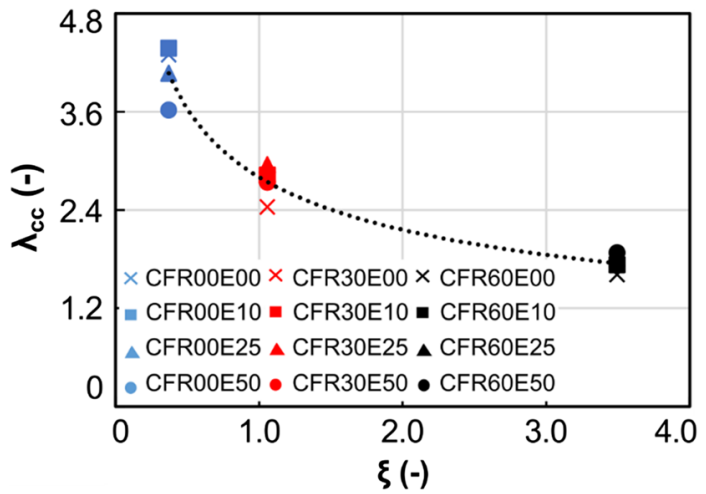

Fig. 8 Relationship between $\lambda_{\mathrm{cc}}$ and $\xi$

$\left(f_{\mathrm{y}} \times A_{\mathrm{s}}\right)$, and the product of concrete compressive strength and the cross-sectional area of the concrete core $\left(f_{\mathrm{c}} \times A_{\mathrm{c}}\right)$.

$N_{\mathrm{ST}}=\frac{f_{\mathrm{y}}}{\left(\frac{1}{A_{\mathrm{s}}}+\frac{e}{W_{\mathrm{pl}}}\right)}$

$\xi=\frac{f_{\mathrm{y}} A_{\mathrm{s}}}{f_{\mathrm{c}} A_{\mathrm{c}}}$.

As shown in Fig. $8, \lambda_{\text {cc }}$ decreases with $\rho_{\text {vr }}$, whilst $\xi$ increases with the rubber content. As the confinement effects occur due to the lateral expansion of the concrete core at ultimate [42] and the RuC exhibits larger lateral dilation than CCM, an enhanced composite action is obtained for RuCFST in comparison with CFST. This effect is captured by the trend in Fig. 8. For an axially loaded circular CFST in compression, the confinement is uniform around the circumference of the tube. In contrast, in specimens subjected to bending only this is non-uniform since the strain varies across the section and is limited to the area of concrete in compression [43]. Unsurprisingly, for R00 CCM the highest $\lambda_{\text {cc }}$ value in Fig. 8 is for axial loading (CFR00E0) and decreases with eccentricity. However, as $\rho_{\mathrm{vr}}$ increases, $\lambda_{\mathrm{cc}}$ becomes relatively constant for R30 and increases for R60 proportionally with the eccentricity level. This effect occurs due to the relatively soft crushing behaviour of $\mathrm{RuC} \mathrm{com-}$ pared to CCM, which is manifested by a larger area in compression, as discussed further below.

Figure 9 shows selected strain profiles $(\varepsilon)$ across the depth for characteristic bending moment levels. As expected, the neutral axis (n.a.), marked with dashed horizontal lines, moves downwards with a decrease in eccentricity, indicating an extension of the compression region. On the other hand, a comparative assessment of neutral axis position as a function of $\rho_{\mathrm{vr}}$ shows a proportional reduction in the tension zone with an increase in $\rho_{\mathrm{vr}}$. For the same level of
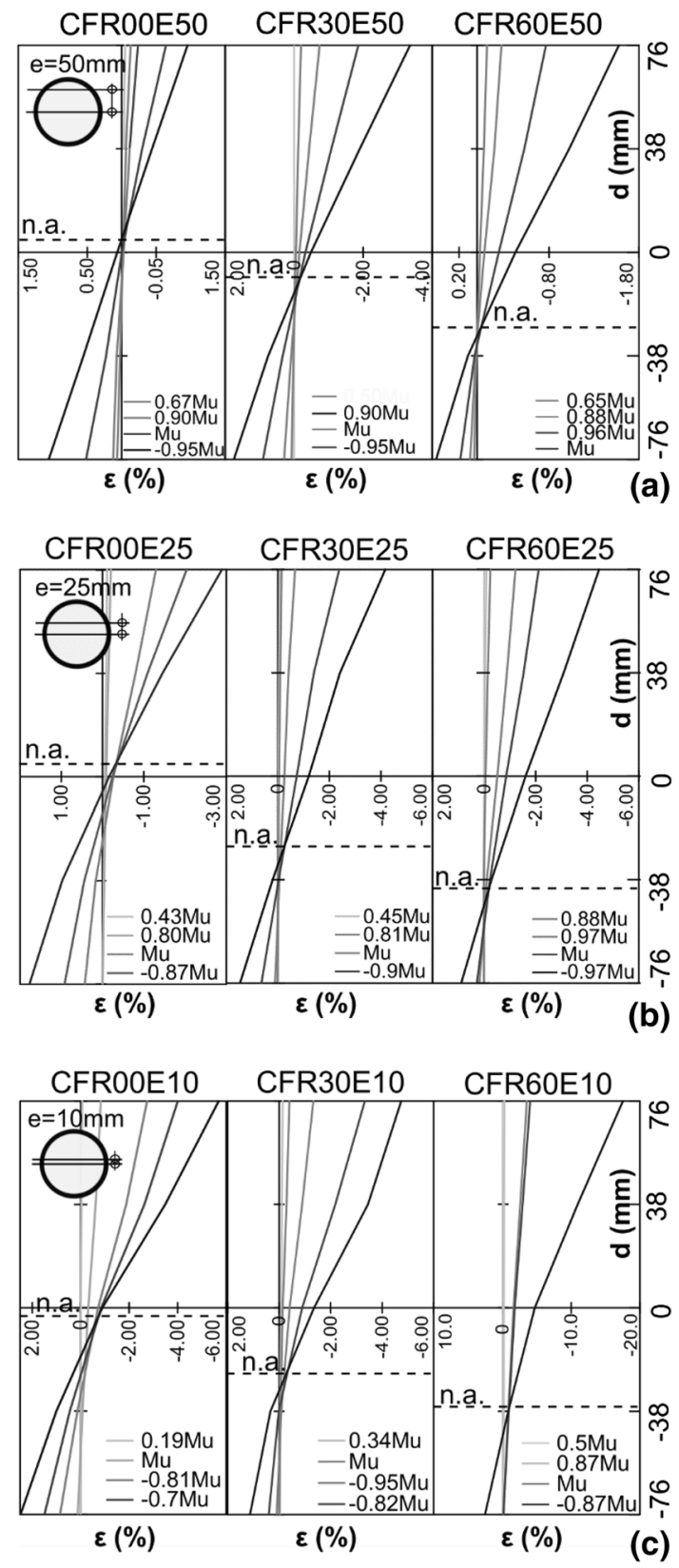

Fig. 9 Representative strain profiles for specimens: a CFRyyE50, b CFRyyE25, CFRyyE10

eccentricity (e.g. $50 \mathrm{~mm}$ ), the tension zone of the RuCFST specimen with $60 \%$ rubber (CFR60E50) settles at about $31 \%$ of the member depth, whilst for the conventional CFST (CFR00E50) this is around 52\% of its section diameter. For comparative purposes only, as shown in Fig. 10, for the members tested bending only, the inelastic stage was characterised by hardening. For consistency, the moment capacity of these members is considered as test bending moment at a longitudinal flexural strain of $1.0 \%$ [44].

As noted above, for relatively large replacement ratios (CFR60E0), there is a significant decrease in compressive 


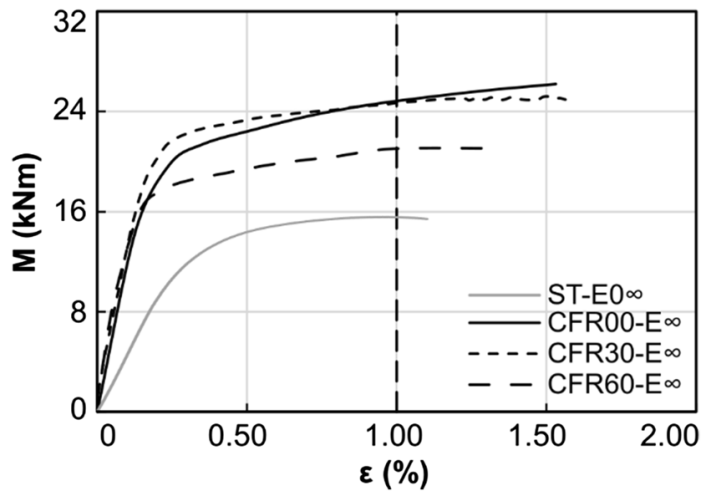

Fig. 10 Moment $(M)$ versus strain $(\varepsilon)$ at mid-span at the extreme tensile fibre

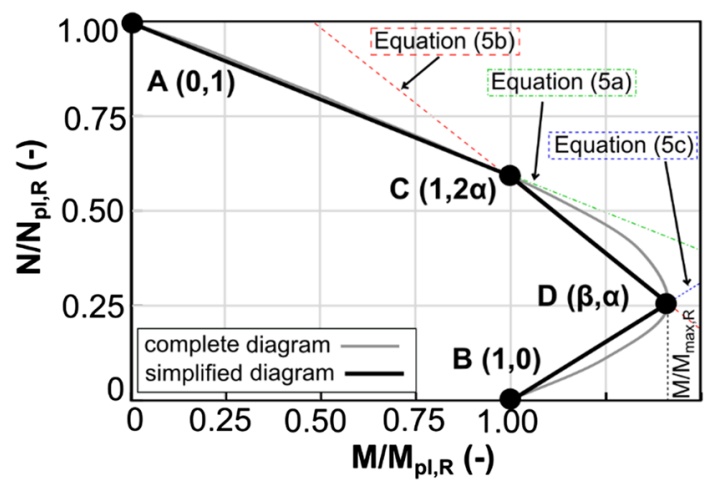

Fig. 11 Schematic representation of simplified and complete $N-M$ diagrams

nominal strength compared to the conventional case (CFR00E0). The reduction from R00 to R30 is by about $43 \%$ and from R00 to R60 is by about $62 \%$. However, in normalised terms, the confined-to-unconfined strength ratios are 1.84, 2.51 and 5.51 for specimens incorporating R00, R30 and $\mathrm{R} 60$ concrete, respectively. The optimum point between all these parameters could possibly be somewhere between R00 and R30 and would require dedicated assessment for specific design situations for which the relative importance of these parameters may differ. To better understand the influence of all these parameters, nonlinear numerical simulations focusing on parameters outside of the tested ranges are currently underway.

\section{Cross-section strength interaction}

Axial-bending $(N-M)$ strength interaction diagrams are typically adopted to characterise the cross-sectional strength under combined loading. A normalised representation of the $N-M$ diagram can be achieved as illustrated in Fig. 11. The grey curve represents the actual interaction under combined loading, whilst the black curve is a simplified version. The latter is characterised by three regions that are bounded by four characteristic pairs $\left(M_{\mathrm{i}} / M_{\mathrm{pl}, \mathrm{R}}, N_{\mathrm{i}} / N_{\mathrm{pl}, \mathrm{R}}\right)$. Points A, B, C and $\mathrm{D}$ represent the maximum axial capacity, the nominal flexural strength, an intermediate case with both axial and bending, and the balance point corresponding to the maximum moment, respectively.

In this section, the test results presented in Sect. 3 are compared with predictions obtained from the application of existing guidelines and a series of nonlinear sectional analyses employing models with fibre elements [45]. Sensitivity studies, focusing on a wide variation of geometrical and material configurations outside of the tested ranges, are also conducted in order to support the development of unified $N-M$ interactions including for RuCFST with relatively high rubber content. In addition to the results from axial stubcolumn tests with relatively low aspect ratios, a database with axial compression test results with $L / D$ in the range of three and above was collated [25-29] and used for validation of the unified $N-M$ diagram.

\subsection{Comparative assessments}

To evaluate the axial-bending $(N-M)$ interaction diagrams for CFST and RuCFST cross-sections, the axial and moment capacities are obtained from existing provisions as well as from sectional analysis considering the material and geometrical properties from Sect. 2.1 [21, 40, 45-47]. It should be noted that for codified assessment based on Eurocode 4 [21], the compressive design resistance of the CFST section is only valid for compressive concrete strength within a specified range (20 MPa $\left.\leq f_{\mathrm{c}} \leq 60 \mathrm{MPa}\right)$ [21]. As shown in Sect. 2.1, R60 concrete is outside this range, whilst R30 concrete is just above the lower bound. Notwithstanding this, an assessment is made herein for all cases, although the specimens with high $\rho_{\mathrm{vr}}$ are not explicitly covered by the code.

The axial capacity of a composite cross-section $\left(N_{\mathrm{pl}, \mathrm{R}}\right)$ is a function of coefficients representing the confinement effect for steel and concrete $\left(\eta_{\mathrm{s}}\right.$ and $\left.\eta_{\mathrm{c}}\right)$, respectively, yield strength of the steel tube $f_{\mathrm{y}}$, its cross-sectional area $A_{\mathrm{s}}$, thickness $t$ and diameter $D$, as well as the cross-sectional area of the concrete core $A_{\mathrm{c}}$ and concrete core strength $f_{\mathrm{c}}$ (Eq. 2a). The term in brackets at the right-hand side of Eq. (2a) is expected to capture the effects of confinement on the axial capacity of the composite section. According to Eurocode 4 [21], both $\eta_{\mathrm{s}}$ and $\eta_{\mathrm{c}}$ are a function of the tube slenderness. For a perfectly plastic behaviour and an eccentricity-to-diameter ratio $e / D=0$, the two factors are $\eta_{\mathrm{s}}=0.75$ and $\eta_{\mathrm{c}}=4.90$. Reduced steel contribution and concrete enhancement occur due to the development of the hoop stress and confinement effect of the concrete, respectively [48]. For eccentricities below $10 \%$ of the diameter, $\eta_{\mathrm{s}}$ and $\eta_{\mathrm{c}}$ are reduced proportionally 
by a factor depending on $e / D$ ratio. Outside these ranges, for $e / D>0.1$, the factors $\eta_{\mathrm{s}}=1.0$ and $\eta_{\mathrm{c}}=0$ imply no contribution from confinement. It is also worth pointing out that the circular hollow sections of the tested specimens are class 2 in bending and/or compression in accordance with Eurocode 3 classification [40].

At the other end of the $N-M$ interaction, the moment capacity of normal CFST composite section under bending only $\left(M_{\mathrm{pl}, \mathrm{R}}\right)$ can be determined from Eq. (2b) [49]. The main parameters required for $M_{\mathrm{pl}, \mathrm{R}}$ are $W_{\mathrm{ps}}, W_{\mathrm{psn}}, f_{\mathrm{y}}, W_{\mathrm{pc}}, W_{\mathrm{pcn},} f_{\mathrm{c}}$, which represent the steel plastic section modulus, steel plastic section modulus from $2 \times h_{\mathrm{n}}$, yield strength of steel tube, concrete plastic section modulus, concrete plastic section modulus from $2 \times h_{\mathrm{n}}$, and strength of concrete core, respectively [21, 49]. The parameter $h_{\mathrm{n}}$ is defined as the distance between the neutral axis and the cross-section centreline.

$N_{\mathrm{pl}, \mathrm{R}}=\eta_{\mathrm{s}} f_{\mathrm{y}} A_{\mathrm{s}}+\left(1+\eta_{\mathrm{c}} \frac{t}{D} \frac{f_{\mathrm{y}}}{f_{\mathrm{c}}}\right) f_{\mathrm{c}} A_{\mathrm{c}}$

$M_{\mathrm{pl}, \mathrm{R}}=\left(W_{\mathrm{ps}}-W_{\mathrm{psn}}\right) f_{\mathrm{y}}+0.5\left(W_{\mathrm{pc}}-W_{\mathrm{pcn}}\right) f_{\mathrm{c}}$

For comparison purposes, only equations to assess the $N-M$ interaction using AISC360 [46] and GB 50936 [47] provisions are shown below. A limitation of the North American code is that it does not cover high-strength materials but allows for the design of slender sections. It is worth noting that the tubular section used for the tests in this paper is compact considering this guideline. Equation (2c) is used to assess the axial capacity $\left(N_{\mathrm{u}, \mathrm{AISC}}\right)$ of a CFST configuration, in which $C_{2}$ is a parameter depending on the section type ( $C_{2}=0.95$ for circular CFST sections). To assess the complete $N-M$ interaction curve, the code permits the use of two methods. The first method is based on a bi-linear interaction model as for steel sections, whilst the second method is based on a four-point envelope such as that illustrated in Fig. $11[46,50]$. For compact sections, the moment capacity $M_{\mathrm{u}, \mathrm{AISC}}$ can be assessed using a plastic stress distribution (Eq. 2b) [46, 49]. For consistency with the Eurocode 4 provisions, the second AISC360 method is used to assess the strength interaction properties.

The GB 50936 design model considers the confinement effects in circular CFST cross-sections when assessing axial load capacity $\left(N_{\mathrm{u}, \mathrm{GB}}\right)($ Eqs. 2e-2g) [51]. The axial capacity is the product of the cross-sectional area $A_{\mathrm{sc}}$ of the CFST member and the compressive design strength of the confining concrete $f_{\text {sc }}$ in CFST column [50] (Eq. 2f). The latter factor $f_{\mathrm{sc}}$ is a function of the confinement factor $\xi$ (Eq. $2 \mathrm{~g}$ ). As pointed out in available literature, the concrete core is under biaxial confinement due to the steel tube having an enhanced compressive strength [52]. The moment capacity $\left(M_{\mathrm{u}, \mathrm{GB}}\right)$ considers an empirical coefficient, dependent on $\xi$, the elastic section modulus $W_{\mathrm{sc}}=\pi D^{3} / 32$, and the compressive strength $f_{\text {sc }}$ (Eq. $2 \mathrm{~h}$ ). Note that Eq. (2h) is a condensed form of the unified GB 50936 models for CFST and circular concrete-filled double-steel tubular (CFDST) in which $\chi=1.0$ [53]. Equations (2e) and (2h) are then used to construct interaction diagrams using an established model [54].

$N_{\mathrm{u}, \mathrm{AISC}}=A_{\mathrm{s}} f_{\mathrm{y}}+C_{2} A_{\mathrm{c}} f_{\mathrm{c}}$

$M_{\mathrm{u}, \mathrm{AISC}}=M_{\mathrm{pl}, \mathrm{R}}$

$N_{\mathrm{u}, \mathrm{GB}}=A_{\mathrm{sc}} f_{\mathrm{sc}}$

$f_{\mathrm{sc}}=\left[1.212+\left(\frac{0.176}{f_{\mathrm{y}}}+0.974\right) \xi+\left(0.031-\frac{0.104 f_{\mathrm{c}}}{14.4}\right) \xi^{2}\right] f_{\mathrm{c}}$

$\xi=\left(A_{\mathrm{s}} f_{\mathrm{y}}\right) /\left(A_{\mathrm{c}} f_{\mathrm{c}}\right)$

$M_{\mathrm{u}, \mathrm{GB}}=(0.963 \sqrt{\xi}-0.214 \xi) W_{\mathrm{sc}} f_{\mathrm{sc}}$.

The $\left(M_{\text {test }}, N_{\text {test }}\right)$ pairs of the tested CFST and RuCFST specimens, and the $N-M$ interaction diagram obtained using Eurocode 4 provisions for which $N_{\mathrm{pl}, \mathrm{R}}$ and $M_{\mathrm{pl}, \mathrm{R}}$ were determined using Eqs. (2a, 2b), are shown in Fig. 12. The comparisons between the tests and code results indicate generally good agreement for the CFST specimens. However, the estimated compression capacities $N_{\mathrm{pl}, \mathrm{R}}$ show unconservative values for RuCFST, below the ultimate capacity measured in the tests $N_{\text {test }}$, noting that the concrete strength of R30 and R60 is below the scope imposed in the code. It is worth noting that Eurocode 4 provides limited information on the design of circular CSFT beam columns incorporating lowstrength concrete. On the other hand, assessments of $M_{\mathrm{pl}, \mathrm{R}}$

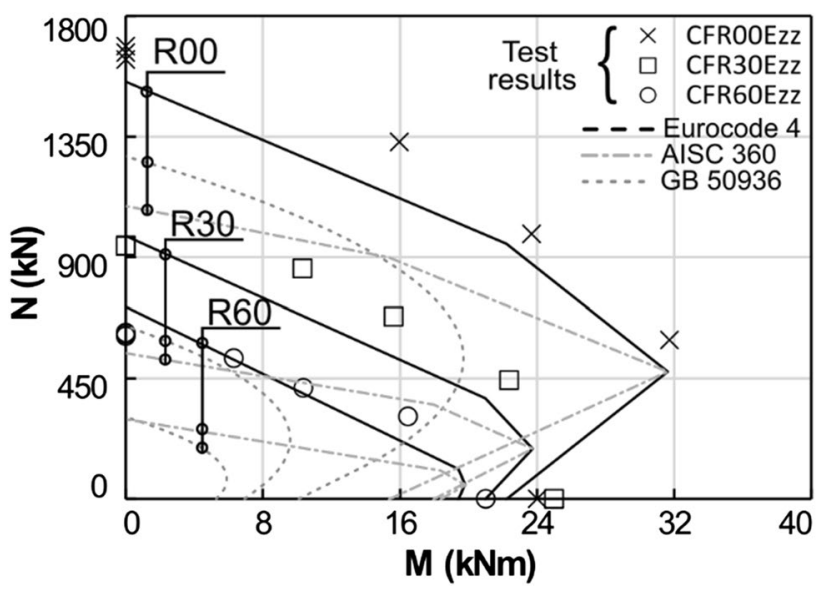

Fig. 12 Comparative assessment between test results and codified procedures [21, 46, 47] 
indicate relatively conservative predictions of the flexural capacity for circular RuCFST members in bending only. The estimated interaction curves using AISC 360 and GB 50936 provisions show conservative values. In all cases, the predicted curves are below the test range and Eurocode 4 estimates. It can be noted that the level of conservatism increases with rubber content, which is largely attributed to the relatively low concrete strengths, which typically would lie outside of the test databases used for validating the design models. As indicated in Fig. 12, Eurocode 4 largely provides more reliable estimates, and it is later modified to better predict the response of RuCFST.

\subsection{Modified axial and bending capacities}

As mentioned above, the axial load-carrying capacity is affected by confinement effects, and as shown in Fig. 8, there is a significant influence from $\rho_{\mathrm{vr}}$ on the confinement enhancement level. The results from the comparative evaluations in the previous section indicate that $N_{\mathrm{pl}, \mathrm{R}}$ is over-predicted compared to the test axial capacity $N_{\text {test }}$. To achieve more reliable estimates, a regression analysis is carried out and a $\rho_{\mathrm{vr}}$-dependent confinement effectiveness factor $\left(\lambda_{\mathrm{rcc}}\right)$ is proposed (Eq. 3a). The $\lambda_{\text {rcc }}$ factor is used to modify the concrete contribution (i.e. term in brackets at the right-hand side of Eq. 2a). The modification can be observed in Eq. (3b). However, as noted before, it should be recalled that the axial compression tests in this study were carried out on relatively short specimens, with L/D of 2.0. These are therefore considered as stub-column tests, which provide useful information on the interaction between the confined infill concrete and the confining steel tube on the cross-section level. However, reliable assessment of axially loaded CFST members, for practical application, would necessitate further dedicated examination and validation for more practical ranges with higher $L / D$ ratios, as the latter can have a notable influence on behaviour.

On the other hand, the assessment of the neutral axis position for specimens subjected to bending and axial force (see
Fig. 9) shows that as $\rho_{\mathrm{vr}}$ increases, there is a proportional reduction in the tension zone length. This effect is more visible for bending-only cases and can be directly correlated to estimates of $M_{\mathrm{pl}, \mathrm{R}}$ using existing codified provisions, which become less conservative with the increase in $\rho_{\text {vr. }}$ In order to obtain more reliable estimates of moment capacity of RuCFST under bending only, a $\rho_{\mathrm{vr}}$-dependent factor $\left(\chi_{\text {rcc }}\right)$ is considered for modifying Eq. $(2 b)$ that considers a plastic stress distribution within the composite section. A linear relationship between $\rho_{\mathrm{vr}}$ and $\chi_{\mathrm{rcc}}$ is used as depicted in Eq. (4a). The $\chi_{\text {rcc }}$ parameter is used to modify the codified equation for $M_{\mathrm{pl}, \mathrm{R}}$ as shown in Eq. (4b).

$\lambda_{\text {rcc }}=\left(1-0.40 \rho_{\mathrm{vr}}\right)$

$N_{\mathrm{pl}, \mathrm{R}}=\eta_{\mathrm{s}} f_{\mathrm{y}} A_{\mathrm{s}}+\lambda_{\mathrm{rcc}}\left(1+\eta_{\mathrm{c}} \frac{t}{D} \frac{f_{\mathrm{y}}}{f_{\mathrm{c}}}\right) f_{\mathrm{c}} A_{\mathrm{c}}$

$\chi_{\mathrm{rcc}}=1-0.05 \rho_{\mathrm{vr}}$

$M_{\mathrm{pl}, \mathrm{R}}=\chi_{\mathrm{rcc}}\left[\left(W_{\mathrm{ps}}-W_{\mathrm{psn}}\right) f_{\mathrm{y}}+0.5\left(W_{\mathrm{pc}}-W_{\mathrm{pcn}}\right) f_{\mathrm{c}}\right]$

The resulting predicted-to-test strength ratios $\left(N_{\text {test }} / N_{\mathrm{pl}, \mathrm{R}}\right)$ with/without the modifying factor $\left(\lambda_{\text {rcc }}\right)$ are plotted against the volumetric rubber ratio $\left(\rho_{\mathrm{vr}}\right)$ in Fig. 13a. Overall, applying the proposed $\lambda_{\text {rcc }}$ factor to existing code formulations (i.e. Eqs. $4 \mathrm{a}, 4 \mathrm{~b}$ with $\lambda_{\text {rcc }}=1.0$ ) provides improved capacity predictions under axial compression. This is shown by the dashed grey line in Fig. 13a that is parallel to $N_{\text {test }} / N_{\mathrm{pl}, \mathrm{R}}=1.0$ in which the steel tube contribution was considered as defined by Eurocode $4\left(\eta_{\mathrm{s}}=0.75\right)$. Note that by considering a full contribution of the steel tube to $N_{\text {pl,Rd }}$ (i.e. $\eta_{\mathrm{s}}=1.00$ ), the predictions are closest to the $N_{\text {test }} / N_{\mathrm{pl}, \mathrm{R}}=1.0$ line. Improved predictions are obtained when Eq. (4b), that accounts for

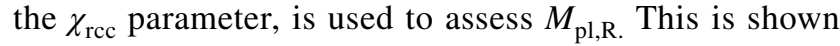
in Fig. 13b in which the estimated $M_{\mathrm{pl}, \mathrm{R}}$ values with and without $\chi_{\text {rcc }}$ are presented. As in the case of $\lambda_{\text {rcc }}$-modified $N_{\mathrm{pl}, \mathrm{R}}$, the $\chi_{\mathrm{rcc}}$-dependent $M_{\mathrm{pl}, \mathrm{R}}$ values in Fig. 13b are more
Fig. 13 Predicted to test strength ratios for: $\mathbf{a} \lambda_{\text {rcc }}, \mathbf{b} \chi_{\text {rcc }}$
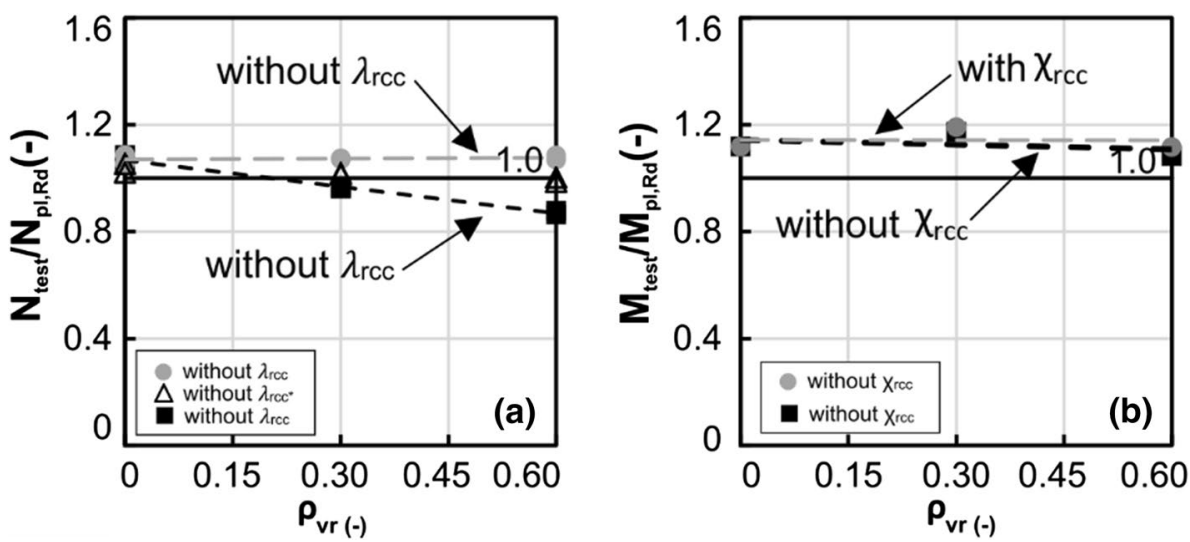
consistently arranged with respect to the $M_{\text {test }} / M_{\mathrm{pl}, \mathrm{R}}=1.0$ line for all ranges of $\rho_{\mathrm{vr}}$.

\subsection{Nonlinear sectional response}

As mentioned before, besides comparison with codified provisions, nonlinear sectional analyses employing models with fibre elements [45] were conducted to assess the $N-M$ interaction curves for tested configurations as well as to undertake sensitivity studies. In these analyses, the crosssection was discretised into fibre elements, and perfect bond was assumed. The circular cross-section of the concrete infill was discretised into ten fibre elements. In order to represent the steel part, closely spaced discrete rebars, having the same total cross-sectional area as the tube, were considered. An initial assessment indicated that the sectional analysis does not capture implicitly confinement effects, offering overly conservative $N-M$ interaction curves, especially in the cases with low bending moments. To overcome this limitation, confinement effects were explicitly incorporated for CFST sections by using the Eurocode 4 confinement factor denoted here as $\kappa_{\mathrm{cc}}$, as an input in the programme [45]. The parameter $\kappa_{\mathrm{cc}}$ is the term in brackets at the right-hand side of Eq. (2b) (i.e. $\left.\kappa_{\mathrm{cc}}=\left[1+\eta_{\mathrm{c}}(t / D)\left(f_{\mathrm{y}} / f_{\mathrm{c}}\right)\right]\right)$. In the sectional assessments, the input stress-strain relationships and the actual concrete contribution were taken into account by adopting the $\rho_{\mathrm{vr}}$-dependent confinement coefficient $\lambda_{\text {rcc }}$ (i.e. $\left.\kappa_{\mathrm{cc}}=\lambda_{\text {rcc } \times}\left[1+\eta_{\mathrm{c}}(t / D)\left(f_{\mathrm{y}} / f_{\mathrm{c}}\right)\right]\right)$.

To validate the above approach, besides the tests from this paper, a total of 40 circular CFST tests in axial compression of compact sections were collated in a database [25-29], and the tests results were compared to those from the analysis. The resulting test-to-sectional analysispredicted strength ratios $\left(N_{\text {test }} / N_{\text {res }}\right)$ with and without the adopted confinement factor are shown in Fig. 14. These results reveal that by adopting a confinement factor $\kappa_{\mathrm{cc}}$ in the sectional analysis programme, much closer agreement

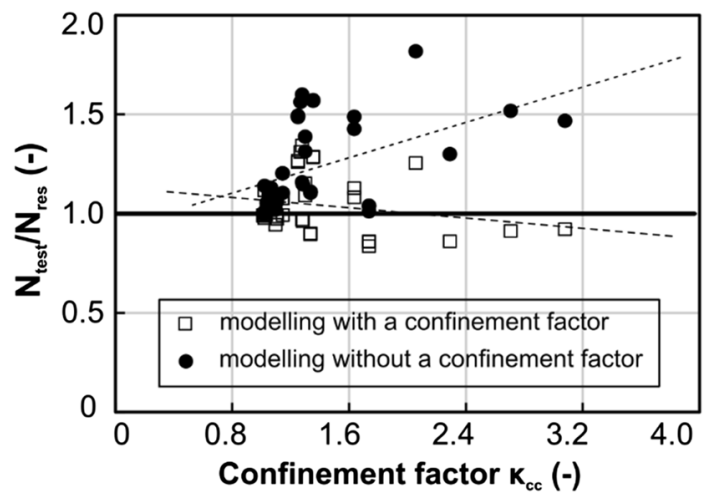

Fig. 14 Comparison between test results and nonlinear section analysis for specimens in compression is obtained. Accordingly, these assumptions were used to undertake sensitivity studies to obtain a detailed insight into the $N-M$ interaction diagram for a wide range of structural parameters.

An orthogonal array method was adopted in the parametric assessment, with three array factors of $\rho_{\mathrm{vr}}, D / t$ and $f_{\mathrm{cr}} / f_{\mathrm{y}}$ for 18 CFST and RuCFST specimens. The ranges of parameters investigated were $\rho_{\mathrm{vr}}=0,0.3,0.6$ and $D / t$ ratios ranging from 29.5 to 71.4 (in $D$ increments of $12 \mathrm{~mm}$ from 152 to $200 \mathrm{~mm}$; $\mathrm{t}$ increments of $0.4 \mathrm{~mm}$ from $2.8 \mathrm{~mm}$ to $8 \mathrm{~mm}$ ). The $f_{\mathrm{c}} / f_{\mathrm{y}}$ ratio was limited to material properties obtained from tests. Note that $\mathrm{f}_{\mathrm{c}}$ denotes the compressive strengths of both conventional and rubberised concretes. A total of 192 models were generated using the sectional analysis procedure and considering the assumptions described above. The main objective was to examine the effect of $D / t, \rho_{\mathrm{vr}}$ and $f_{\mathrm{cr}} / f_{\mathrm{y}}$ on the $N-M$ interaction of RuCFST sections.

\subsection{Simplified axial-bending relationships}

As mentioned above, axial-bending $(N-M)$ interaction diagrams for RuCFST cross-sections can be developed using sectional analysis procedures or alternatively, for practical design procedures, through more simplified methods. The latter can be represented by three regions that are bounded by four characteristic pairs $\left(M_{\mathrm{i}} / M_{\mathrm{pl}, \mathrm{R}}, N_{\mathrm{i}} / N_{\mathrm{pl}, \mathrm{R}}\right)$. Points A, B, $\mathrm{C}$ and $\mathrm{D}$ from Fig. 11 represent the maximum axial capacity, the nominal flexural strength, an intermediate case with both axial and bending and the balance point corresponding to the maximum moment, respectively.

Two coefficients $(\alpha, \beta)$ are introduced to represent the $N-M$ values at Points $\mathrm{C}$ and $\mathrm{D}$. Considering the unknowns $\alpha$ and $\beta$, Eqs. (5a)-(5c) are proposed, in which $N_{\mathrm{i}}, M_{\mathrm{i}}, N_{\mathrm{pl}, \mathrm{R}}$ and $M_{\mathrm{pl}, \mathrm{R}}$ are the axial load capacity and plastic moment capacity in a particular range, the axial load capacity under axial compression from Eqs. (3a), (3b) and the plastic moment capacity under bending only from Eqs. (4a), (4b), respectively.

$$
\begin{aligned}
& \frac{N_{i}}{N_{\mathrm{pl}, \mathrm{R}}}+(1-2 \alpha) \frac{M_{i}}{M_{\mathrm{pl}, \mathrm{R}}}-1=0 \rightarrow 2 \alpha \geq \frac{N_{i}}{N_{\mathrm{pl}, \mathrm{R}}}>1.0 \\
& \frac{N_{i}}{N_{\mathrm{pl}, \mathrm{R}}}+\left(\frac{\alpha}{\beta-1}\right) \frac{M_{i}}{M_{\mathrm{pl}, \mathrm{R}}}-\left(2 \alpha+\frac{\alpha}{\beta-1}\right)=0 \rightarrow \alpha \geq \frac{N_{i}}{N_{\mathrm{pl}, \mathrm{R}}}>2 \alpha
\end{aligned}
$$

$\left(\frac{1-\beta}{\alpha}\right) \frac{N_{i}}{N_{\mathrm{pl}, \mathrm{R}}}+\frac{M_{i}}{M_{\mathrm{pl}, \mathrm{R}}}-1=0 \rightarrow 0 \geq \frac{N_{i}}{N_{\mathrm{pl}, \mathrm{R}}}>\alpha$

where $M_{\mathrm{pl}, \mathrm{R}} \leq M_{\max , \mathrm{R}}$.

As noted before, the performance of RuCFST crosssections is strongly affected by the presence of rubber, which has direct implications on the confinement levels 
achieved. The application of Eqs. (2a), (2b) in conjunction with Eqs. (5a)-(5c) would provide reliable estimates for conventional CFST. However, based on the experimental observations in Sect. 3 and the comparative assessments from Sect. 4.1, these would be unconservative for relatively high levels of $\rho_{\mathrm{vr}}$ The performance of CFST sections is also influenced by other geometric and material parameters such as the tube diameter-to-thickness ratio, $D / t$, concrete strength $f_{\mathrm{c}}$ and steel strength $f_{\mathrm{y}}$. As mentioned above, the influence of these parameters on the $N-M$ interaction of CFST and RuCFST cross-sections was investigated by means of nonlinear sectional analyses.

To enable the development of a $\rho_{\mathrm{vr}}$-dependent simplified $N-M$ assessment method, the normalised maximum moment $(\beta)$ and the normalised axial load $(\alpha)$ are assessed from the nonlinear sensitivity studies described in Sect. 4.3 by varying the parameters $D / t, \rho_{\mathrm{vr}}$ and $f_{\mathrm{c}} / f_{\mathrm{y}}$. A linear regression method was employed to quantify the influence of each factor on $\alpha$ and $\beta$. Both $\rho_{\mathrm{vr}}$ and $f_{\mathrm{c}} / f_{\mathrm{y}}$ showed significant influence on Points B, C, D and B with various geometric ratios $(D / t)$. Variations of $\alpha$ and $\beta$ against key parameters are plotted in Fig. 15. As indicated, both $\alpha$ and $\beta$ increase as $D / t$ and $f_{\mathrm{cr}} / f_{\mathrm{y}}$ increase, but decrease proportionally with $\rho_{\mathrm{vr}}$. These assessments enabled the development of two expressions to evaluate $\alpha$ and $\beta$ (Eqs. 6a, 6b). Note that only sections that are representative of class 1 or class 2 under bending and/or compression are considered [40].

$\alpha=\left(1-0.05 \rho_{\mathrm{vr}}\right)\left(1.30 \frac{f_{\mathrm{rc}}}{f_{\mathrm{y}}}+0.045\right)\left[1-0.25\left(\frac{D}{t}\right)^{-1}\right]$

$$
\begin{aligned}
& \beta=\left(1-0.10 \rho_{\mathrm{vr}}\right)\left(1.25 \frac{f_{\mathrm{rc}}}{f_{\mathrm{y}}}+1\right)\left[1-0.90\left(\frac{D}{t}\right)^{-1}\right] \\
& f_{\mathrm{rc}}=\frac{1}{1+2\left(\frac{3 \lambda \rho_{\mathrm{vr}}}{2}\right)^{3 / 2}} f_{\mathrm{c} 0},
\end{aligned}
$$

where $\lambda$ is function of the replaced mineral aggregate size

$$
\lambda=\mid \begin{aligned}
& 2.43 \rightarrow d_{\mathrm{g}, \text { repl }} \in(0,5) \\
& 2.90 \rightarrow d_{\mathrm{g}, \text { repl }} \in\left(0, d_{\mathrm{g}, \max }\right) . \\
& 2.08 \rightarrow d_{\mathrm{g}, \text { repl }} \in\left(5, d_{\mathrm{g}, \text { max }}\right)
\end{aligned}
$$

Figure 16 shows predictions for the $N-M$ diagram, obtained using the proposed expressions which are compared with the test results. It can be observed that the predictions of Eqs. (3a, 3b)-(5a, 5b, 5c) using the characteristic pairs $(\beta, \alpha)$ from Eq. (6a), (6b) offer more reliable estimates for the complete range of $N-M$ interactions in comparison with estimates of existing codified provisions [21, 46, 47]. This modified approach is therefore suitable for capturing the influence of relatively high rubber content on the resistance of CFST configurations with class 1 or class 2 steel cross-sections.

As noted before, it should be recalled that the axial compression tests in this study were carried out on relatively short specimens, with $L / D$ of 2.0. To overcome this limitation, a database of specimens with $L / D>3.0$ was collated and employed for validation of the modified $N-M$ interaction model described in Sect. 4.2. However, as noted in the literature, axial tests with relatively low aspect ratios can be considered as stub-columns, which offer useful information
Fig. 15 Variation of $\alpha$ and $\beta$ with respect to parameters $\rho_{\mathrm{vr}}$, $f_{\mathrm{c}} / f_{\mathrm{y}}$ and $D / t$

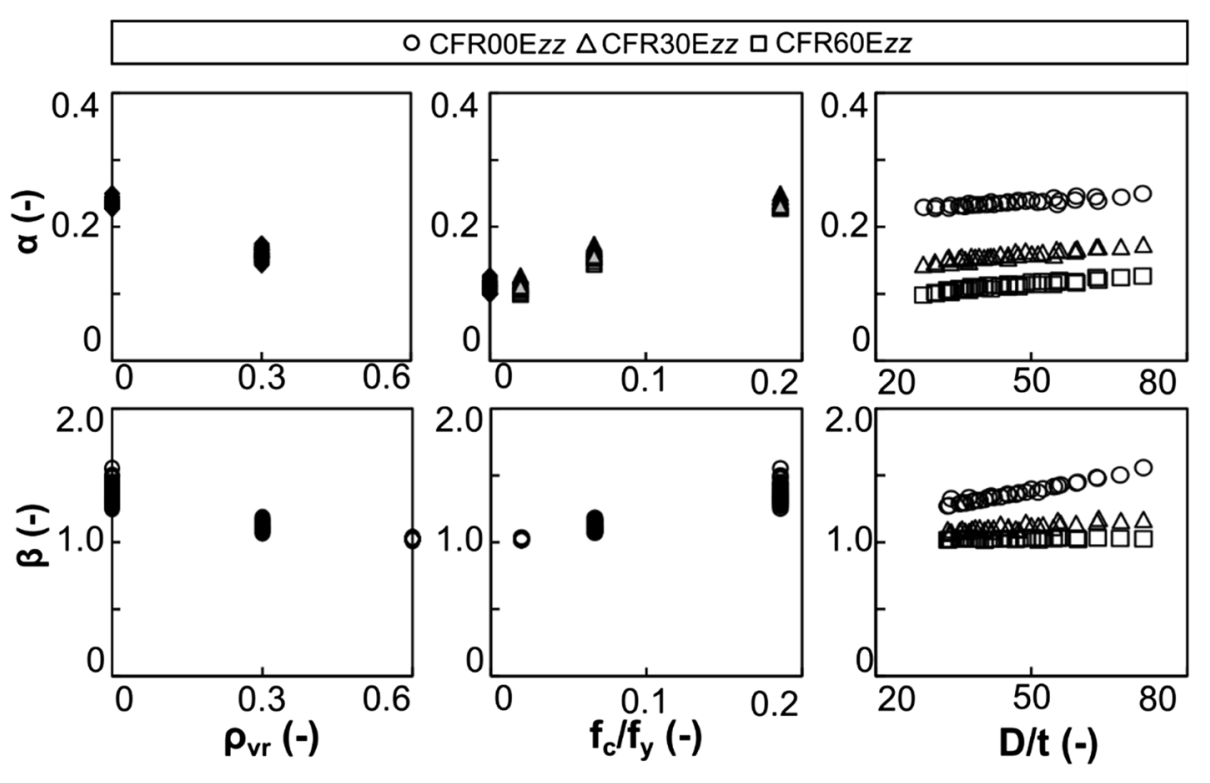



test results, estimates of Eqs. (3a, 3b-6a, 6b, 6c, 6d) and codified provisions $[21,47,486]$ for specimens: a CFR00Ezz, b CFR30Ezz, c CFR60Ezz
Fig. 16 Comparison between
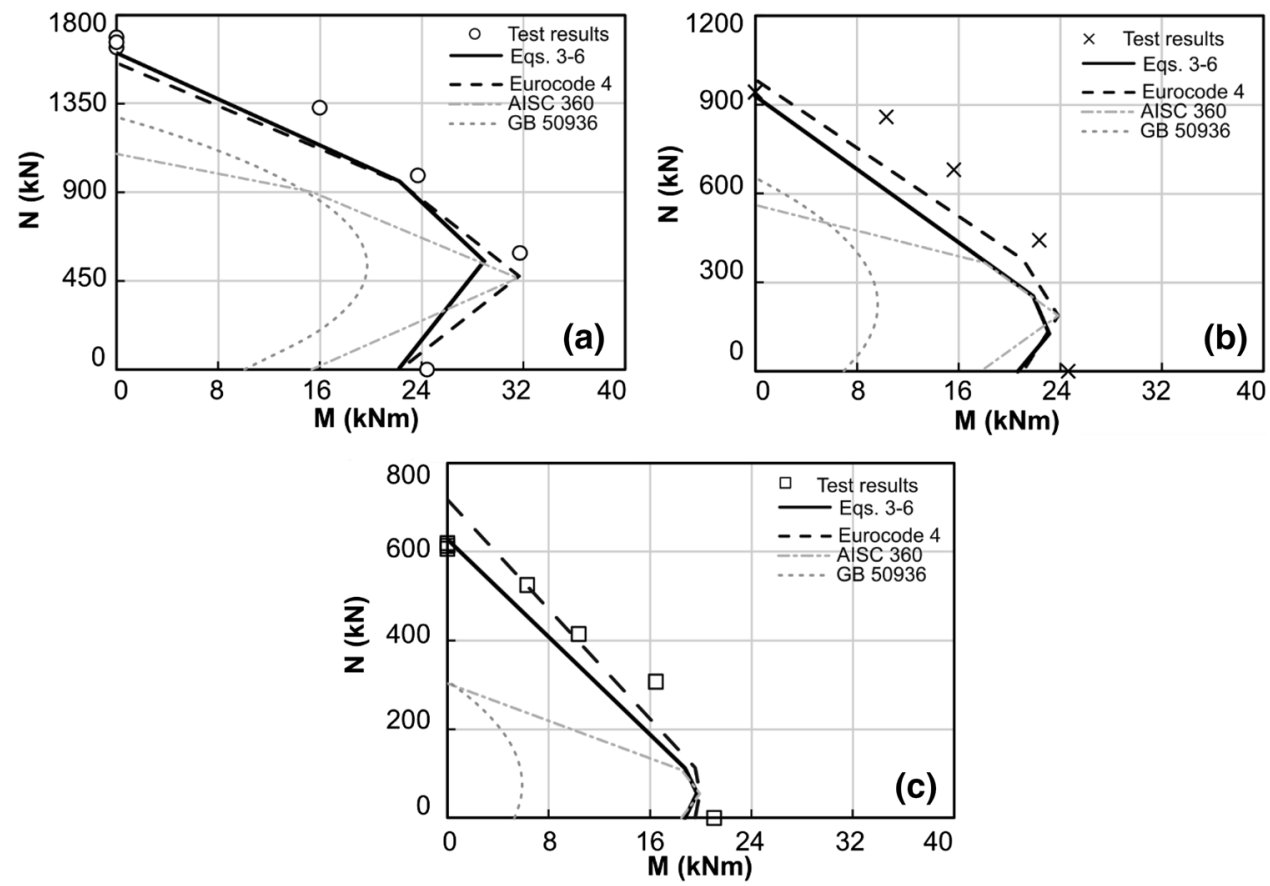

on the material confinement effects provided by the steel tube to the infilled concrete. For practical application at member level, further dedicated examination and validation for higher $L / D$ ratios would be required, as the latter can have a notable influence on behaviour. On the other hand, the eccentric and bending tests aspect ratios $(L / D=4.0)$ are within typical ranges in which both end effects and influence from slenderness are minimised or eliminated $[30,31]$.

\section{Concluding remarks}

Experimental and analytical investigations into the response of rubberised concrete within circular CFST and RuCFST cross-sections were described in this paper, with particular focus on relatively high rubber content of up to $60 \%$. The tests included a total of 30 specimens subjected to compression, eccentric compression or bending. A detailed account of the test results and observations were presented, with emphasis on the cross-section strength and confinement. Comparative assessments between the test results and existing recommendations were also undertaken alongside sensitivity studies to assess the influence of key geometric and material parameters, leading to proposed simplified expressions for representing the axial-bending cross-section interaction diagrams. The main conclusions drawn are outlined below.

Experimental observations showed that radial expansion and outward folding failure modes were observed in the axial tests on short specimens, which were highly dependent on the proportion of rubber in the concrete infill. A high amount of elastic energy is accumulated within the RuCFST specimens, as illustrated by the significant spring-back effect of the rubberised infill which increased with the amount of rubber. In the eccentric tests, a combination of axial and flexural buckling was observed without steel fracture in tension. A similar folding failure mechanism was observed for all specimens (filled tubes and hollow tubes) subjected to three-point bending. Crack patterns observed on the concrete core after removal of the steel tube showed flexural-type failure modes without influence from shear.

The response of RuCFST specimens typically exhibited enhanced confinement characteristics with the confined-tounconfined strength ratios increasing proportionally with the rubber content, yet at the expense of lower nominal loadcarrying capacities. This was manifested by a transition from bi-linear post-peak softening response for $0 \%$ rubber to postpeak hardening for $60 \%$ rubber. Detailed test measurements by means of digital image correlation techniques showed that for specimens under combined loading subjected to the same level of eccentricity, the compression zone extended proportionally with the rubber content. This behaviour indicated improved confinement even for cases of combined loading with significant bending.

Axial-bending interaction curves for RuCFST cross-sections were compared with predictions from existing codified tional analyses, that were validated against the tests results from this paper and a collated database on specimens with a range of aspect ratios. It was shown that existing procedures are unable to predict in a reliable manner the strength of RuCFST cross-sections under axial loading or bending-only, procedures as well as those resulting from nonlinear sec- 
particularly for cases with relatively high rubber content. Accordingly, rubber content-dependent factors were suggested for use in conjunction with code expressions to obtain improved estimates of the axial and bending cross-section capacity, noting that further dedicated experimental assessments and validations for axially loaded rubberised concrete-infilled tubular members of various length-to-diameter ratios are required. Additional nonlinear numerical sectional assessments were also carried out to assess the influence of key parameters on the strength interaction properties. The tests results, added to those from the numerical studies, enabled the development of more reliable simplified expressions for determining the cross-section strength interaction under combined loading conditions.

Acknowledgements The first author wishes to acknowledge the scholarship funding provided by the Turkish Ministry of National Education. The authors would additionally like to thank the technical staff of the Structures Laboratories at Imperial College London, particularly $\mathrm{Mr}$ T Stickland, for their assistance with the tests. The support of Adria Abruzzo, Breedon Group, Elkem and Sika through material provision is also gratefully acknowledged.

Author contribution AM was involved in conceptualisation, methodology, investigation, formal analysis and writing — original draft; DVB performed conceptualisation, methodology, investigation, writing-original draft, supervision; AYE contributed to conceptualisation, methodology, writing - review and editing, funding acquisition and supervision.

\section{Declaration}

Conflict of interest The authors declare that they have no conflict of interest.

Open Access This article is licensed under a Creative Commons Attribution 4.0 International License, which permits use, sharing, adaptation, distribution and reproduction in any medium or format, as long as you give appropriate credit to the original author(s) and the source, provide a link to the Creative Commons licence, and indicate if changes were made. The images or other third party material in this article are included in the article's Creative Commons licence, unless indicated otherwise in a credit line to the material. If material is not included in the article's Creative Commons licence and your intended use is not permitted by statutory regulation or exceeds the permitted use, you will need to obtain permission directly from the copyright holder. To view a copy of this licence, visit http://creativecommons.org/licenses/by/4.0/.

\section{References}

1. Bompa DV, Elghazouli AY, Xu B, Stafford PJ, Ruiz-Teran AM. Experimental assessment and constitutive modelling of rubberised concrete materials. Constr Build Mater. 2017;137:246-60. https:// doi.org/10.1016/j.conbuildmat.2017.01.086.

2. Strukar K, Šipoš TK, Miličević I, Bušić R. Potential use of rubber as aggregate in structural reinforced concrete element-a review. Eng Struct. 2019;188:452-68. https://doi.org/10.1016/j.engstruct. 2019.03.031.
3. Raffoul S, Garcia R, Pilakoutas K, Guadagnini M, Medina NF. Optimisation of rubberised concrete with high rubber content: an experimental investigation. Constr Build Mater. 2016;124:391404. https://doi.org/10.1016/j.conbuildmat.2016.07.054.

4. Son KS, Hajirasouliha I, Pilakoutas K. Strength and deformability of waste tyre rubber-filled reinforced concrete columns. Constr Build Mater. 2011;25(1):218-26. https://doi.org/10.1016/j.conbu ildmat.2010.06.035.

5. Elghazouli AY, Bompa DV, Xu B, Ruiz-Teran AM, Stafford PJ. Performance of rubberised reinforced concrete members under cyclic loading. Eng Struct. 2018;166:526-45. https://doi.org/10. 1016/j.engstruct.2018.03.090.

6. Bompa DV, Elghazouli AY. Stress-strain response and practical design expressions for FRP-confined recycled tyre rubber concrete. Constr Build Mater. 2020;237:117633. https://doi.org/10. 1016/j.conbuildmat.2019.117633.

7. Raffoul S, Escolano-Margarit D, Garcia R, Guadagnini M, Pilakoutas K. Constitutive model for rubberized concrete passively confined with FRP laminates. J Compos Constr. 2019;23(6):04019044. https://doi.org/10.1061/(ASCE)CC.19435614.0000972.

8. Bompa DV, Elghazouli AY. Behaviour of confined rubberised concrete members under combined loading conditions. Mag Concr Res. 2019. https://doi.org/10.1680/jmacr.19.00121.

9. Elchalakani M, Hassanein MF, Karrech A, Yang B. Experimental investigation of rubberised concrete-filled double skin square tubular columns under axial compression. Eng Struct. 2018;171:730-46. https://doi.org/10.1016/j.engstruct.2018.05. 123.

10. Han LH, Li W, Bjorhovde R. Developments and advanced applications of concrete-filled steel tubular (CFST) structures: members. J Constr Steel Res. 2014;100:211-28. https://doi.org/10.1016/j. jcsr.2014.04.016.

11. Nematzadeh M, Hajirasouliha I, Haghinejad A, Naghipour M. Compressive behaviour of circular steel tube-confined concrete stub columns with active and passive confinement. Steel Compos Struct. 2017;24(3):323-37. https://doi.org/10.12989/scs.2017. 24.3.323.

12. Zhu JY, Chan TM. Experimental investigation on steel-tube-confined-concrete stub column with different cross-section shapes under uniaxial-compression. J Constr Steel Res. 2019;162:105729. https://doi.org/10.1016/j.jcsr.2019.105729.

13. Duarte APC, Silva BA, Silvestre N, De Brito J, Júlio E, Castro JM. Tests and design of short steel tubes filled with rubberised concrete. Eng Struct. 2016;112:274-86. https://doi.org/10.1016/j. engstruct.2016.01.018.

14. Silva A, Jiang Y, Castro JM, Silvestre N, Monteiro R. Experimental assessment of the flexural behaviour of circular rubberized concrete-filled steel tubes. J Constr Steel Res. 2016;122:557-70. https://doi.org/10.1016/j.jcsr.2016.04.016.

15. Elchalakani M, Hassanein MF, Karrech A, Fawzia S, Yang B, Patel VI. Experimental tests and design of rubberised concretefilled double skin circular tubular short columns. I. Structures. 2018;15:196-210. https://doi.org/10.1016/j.istruc.2018.07.004.

16. Abuzaid O, Nabilah AB, Safiee NA, Azline MN. Rubberized concrete filled steel tube. In: IOP Conference Series: Earth and Environmental Science (vol. 357(1)). IOP Publishing; 2019. p. 012014. https://doi.org/10.1088/1755-1315/357/1/012014

17. Duarte APC, Silva BA, Silvestre N, De Brito J, Júlio E, Castro JM. Experimental study on short rubberized concrete-filled steel tubes under cyclic loading. Compos Struct. 2016;136:394-404. https://doi.org/10.1016/j.compstruct.2015.10.015.

18. Dong M, Elchalakani M, Karrech A, Fawzia S, Ali MSM, Yang B, $\mathrm{Xu}$ SQ. Circular steel tubes filled with rubberised concrete under combined loading. J Constr Steel Res. 2019;162:105613. https:// doi.org/10.1016/j.jcsr.2019.05.003. 
19. Lee SH, Uy B, Kim SH, Choi YH, Choi SM. Behavior of highstrength circular concrete-filled steel tubular (CFST) column under eccentric loading. J Constr Steel Res. 2011;67(1):1-13. https://doi.org/10.1016/j.jcsr.2010.07.003.

20. Silva A, Jiang Y, Castro JM, Silvestre N, Monteiro R. Monotonic and cyclic flexural behaviour of square/rectangular rubberized concrete-filled steel tubes. J Constr Steel Res. 2017;139:385-96. https://doi.org/10.1016/j.jcsr.2017.09.006.

21. CEN European Committee for Standardization) 2004 EN 19941-1 Eurocode 4: Design of composite steel and concrete structures-Part 1-1: General rules and rules for buildings. London: British Standards.

22. Zhang Y, Zhao J, Yuan W. Study on compressive bearing capacity of concrete-filled square steel tube column reinforced by circular steel tube inside. J Civ Eng Manag. 2013;19(6):787-95. https:// doi.org/10.3846/13923730.2013.799088.

23. Shen Q, Wang J, Wang J, Ding Z. Axial compressive performance of circular CFST columns partially wrapped by carbon FRP. J Constr Steel Res. 2019;155:90-106. https://doi.org/10.1016/j.jcsr. 2018.12.017.

24. Chang X, Ru ZL, Zhou W, Zhang YB. Study on concrete-filled stainless steel-carbon steel tubular (CFSCT) stub columns under compression. Thin Walled Struct. 2013;63:125-33. https://doi. org/10.1016/j.tws.2012.10.002.

25. O'Shea MD, Bridge RQ. Design of circular thin-walled concrete filled steel tubes. Struct Eng. 2000;126:1295-303. https://doi.org/ 10.1061/(ASCE)0733-9445(2000)126:11(1295).

26. Han LH, Yao GH. Experimental behaviour of thin-walled hollow structural steel (HSS) columns filled with self-consolidating concrete (SCC). Thin Walled Struct. 2004;42(9):1357-77. https:// doi.org/10.1016/j.tws.2004.03.016.

27. O'Shea MD, Bridge RQ. Tests on circular thin-walled steel tubes filled with medium and high strength concrete. Res. Rep. R755, Dept. of Civ. Engrg., University of Sydney, Sydney, Australia; 1997.

28. Wang W, Ma H, Li Z, Tang Z. Size effect in circular concretefilled steel tubes with different diameter-to-thickness ratios under axial compression. Eng Struct. 2017;151:554-67. https://doi.org/ 10.1016/j.engstruct.2017.08.022.

29. Lai MH, Ho JCM. Uni-axial compression test of concretefilled-steel-tube columns confined by tie bars. Procedia Eng. 2013;57:662-9. https://doi.org/10.1016/j.proeng.2013.04.084.

30. Yu ZW, Ding FX, Cai CS. Experimental behavior of circular concrete-filled steel tube stub columns. J Constr Steel Res. 2007;63(2):165-74. https://doi.org/10.1016/j.jcsr.2006.03.009.

31. Lai MH, Ho JCM. Effect of continuous spirals on uni-axial strength and ductility of CFST columns. J Constr Steel Res. 2015;104:235-49. https://doi.org/10.1016/j.jcsr.2014.10.007.

32. CEN (European Committee for Standardization) (2009) EN 12390-2:2009, Testing Hardened Concrete: Making and Curing Specimens for Strength Tests, Brussels (Belgium), CEN.

33. CEN (European Committee for Standardization) (2001) EN 10002-1 Metallic materials-Tensile testing-Part 1: Method of test at ambient temperature, London: British Standards Institution

34. LaVision, n.d. Digital Image Correlation (DIC). https://www.lavis ion.de/en/techniques/dic-dvc/. Accessed 23 Dec 2020.

35. Buchanan C, Gardner L, Liew A. The continuous strength method for the design of circular hollow sections. J Constr Steel Res. 2016;118:207-16. https://doi.org/10.1016/j.jcsr.2015.11.006.

36. Cedron F, Elghazouli AY. Seismic performance of single layer steel cylindrical lattice shells. J Constr Steel Res. 2019;163:105772. https://doi.org/10.1016/j.jcsr.2019.105772.

37. Ismail MK, Hassan AA. Ductility and cracking behavior of reinforced self-consolidating rubberized concrete beams. J Mater Civ Eng. 2017;29(1):04016174. https://doi.org/10.1061/(ASCE)MT. 1943-5533.0001699.
38. Turki M, Bretagne E, Rouis MJ, Quéneudec M. Microstructure, physical and mechanical properties of mortar-rubber aggregates mixtures. Constr Build Mater. 2009;23(7):2715-22. https://doi. org/10.1016/j.conbuildmat.2008.12.019.

39. Piquer A, Ibañez C, Hernández-Figueirido D. Structural response of concrete-filled round-ended stub columns subjected to eccentric loads. Eng Struct. 2019;184:318-28. https://doi.org/10.1016/j. engstruct.2019.01.091.

40. CEN (European Committee for Standardization) (2005) EN 19931-1. Eurocode 3: Design of steel structures. Part 1.1: General rules and rules for buildings. Brussels, Belgium: Comite Europeen de Normalisation.

41. He L, Lin S, Jiang H. Confinement effect of concrete-filled steel tube columns with infill concrete of different strength grades. Front Mater. 2019;6:71. https://doi.org/10.3389/fmats.2019. 00071.

42. Shams M, Saadeghvaziri MA. State of the art of concrete-filled steel tubular columns. Struct J. 1997;94(5):558-71.

43. Gunawardena YK, Aslani F, Uy B, Kang WH, Hicks S. Review of strength behaviour of circular concrete filled steel tubes under monotonic pure bending. J Constr Steel Res. 2019;158:460-74. https://doi.org/10.1016/j.jcsr.2019.04.010.

44. Hou CC, Han LH, Wang QL, Hou C. Flexural behavior of circular concrete filled steel tubes (CFST) under sustained load and chloride corrosion. Thin Walled Struct. 2016;107:182-96. https://doi. org/10.1016/j.tws.2016.02.020.

45. Bentz EC. Sectional analysis of reinforced concrete members. Toronto: University of Toronto; 2000.

46. AISC 360-16. Specification for structural steel buildings. Chicago: American Institute of Steel Construction; 2016.

47. GB 50936-2014. Technical code for concrete filled steel tubular structures. Ministry of Housing and Urban-Rural Development of the People's Republic of China. 2014.

48. Dundu M. Compressive strength of circular concrete filled steel tube columns. Thin Walled Struct. 2012;56:62-70. https://doi.org/ 10.1016/j.tws.2012.03.008.

49. Liew JR, Xiong M. Design guide for concrete filled tubular members with high strength materials to Eurocode 4. Research Publishing; 2015.

50. Thai HT, Thai S, Ngo T, Uy B, Kang WH, Hicks SJ. Reliability considerations of modern design codes for CFST columns. J Constr Steel Res. 2020;177:106482.

51. Patel VI, Hassanein MF, Thai HT, Al Abadi H, Elchalakani M, Bai Y. Ultra-high strength circular short CFST columns: axisymmetric analysis, behaviour and design. Eng Struct. 2019;179:26883. https://doi.org/10.1016/j.engstruct.2018.10.081999.

52. Tan K, Nichols JM. Properties of high-strength concrete filled steel tube columns. Mod Civ Struct Eng. 2017;1(1):58-77. https:// doi.org/10.22606/mcse.2017.11005.

53. Zhao H, Wang R, Lam D, Hou CC, Zhang R. Behaviours of circular CFDST with stainless steel external tube: slender columns and beams. Thin Walled Struct. 2020;158:107172. https://doi.org/ 10.1016/j.tws.2020.107172fullGBforDST.

54. Tao Z, Han LH, Zhao XL. Behaviour of concrete-filled double skin (CHS inner and CHS outer) steel tubular stub columns and beam-columns. J Constr Steel Res. 2004;60(8):1129-58. https:// doi.org/10.1016/j.jcsr.2003.11.008.

Publisher's Note Springer Nature remains neutral with regard to jurisdictional claims in published maps and institutional affiliations. 